\title{
Hybrid Materials for Molecular Sieves
}

\author{
Johan E. ten Elshof
}

\section{Contents}

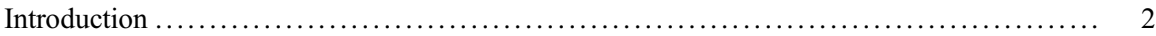

Historical Outline of Microporous Ceramic Membrane Development $\ldots \ldots \ldots \ldots \ldots \ldots \ldots \ldots \ldots$

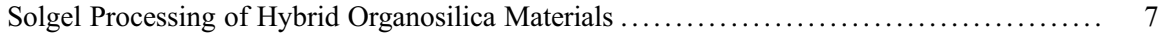

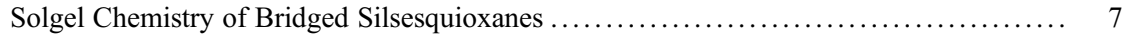

Structure Evolution in Sols and Thin Films .................................. 9

Pore Structure in Thermally Consolidated Materials ............................ 11

Supported Membrane Preparation and Determination of Pore Size Distribution ............ 13

Membrane Preparation .................................................. 13

Determination of Membrane Pore Size Distribution .............................. 15

Hybrid Organosilica Membranes for Gas Separation and Pervaporation $\ldots \ldots \ldots \ldots \ldots \ldots \ldots \ldots$

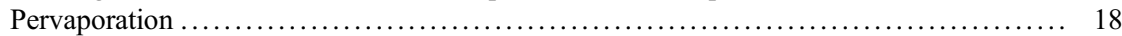

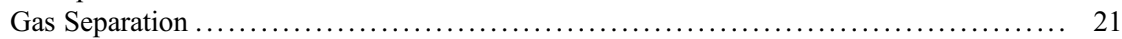

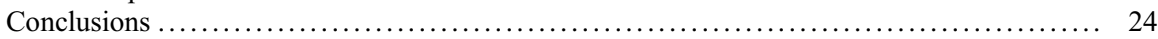

References $\ldots \ldots \ldots \ldots \ldots \ldots \ldots \ldots \ldots \ldots \ldots \ldots \ldots \ldots \ldots \ldots \ldots \ldots \ldots \ldots \ldots \ldots \ldots \ldots \ldots \ldots \ldots \ldots \ldots \ldots \ldots \ldots \ldots, 24$

\begin{abstract}
Hybrid microporous organosilica membranes for molecular separations made by acid-catalyzed solgel synthesis from bridged silsesquioxane precursors have demonstrated good performance in terms of flux and selectivity and remarkable hydrothermal stability in various pervaporation and gas separation processes. The availability of wide range of $\alpha, \omega$-bis(trialkoxysilyl)alkane and 1,4-bis (triethoxysilyl)benzene precursors allows tuning of membrane properties such as pore size and chemistry. This chapter presents an overview of the synthesis and application of hybrid organosilica microporous membranes in liquid and gas
\end{abstract}

\footnotetext{
J.E. ten Elshof $(\bowtie)$

MESA+ Institute for Nanotechnology, University of Twente, Enschede, The Netherlands

e-mail: j.e.tenelshof@utwente.nl
} 
separation processes. After a concise discussion of the history of solgel-derived microporous ceramic membranes for molecular separations, the solgel chemistry of bridged silsesquioxanes and all relevant processing steps needed to obtain a supported microporous films suitable for molecular separations are discussed. The performance of these membranes is correlated with the membrane compositional properties, such as nature, stiffness and length of the bridging group, and details of the solgel process.

\section{Introduction}

Separation processes are among the more energy-intensive process steps in the chemical and petrochemical industries. Separation of liquids and gases on molecular scale using membranes offers an interesting energy-efficient alternative to conventional large-scale separation processes such as distillation and selective adsorption. Molecular separation membranes are expected to play an important role in reaching the environmental goal to reduce $\mathrm{CO}_{2}$ emissions (Adewole et al. 2013; Zhang et al. 2013), but they can also find application in the dehydration of water from organic solvents and bio-based fuels (van Veen et al. 2011).

Ceramic membranes are particularly interesting since ceramics are well known for their high chemical and thermal stability, which makes them potentially promising candidates for use under conditions where polymeric or zeolite membranes are not stable. Nevertheless, it should be kept in mind that a (micro)structure with very small meso- or micropores $(<50 \mathrm{~nm})$, small radii of curvature in the pore walls, and a large specific surface area is not intrinsically stable even when it is ceramic. Surface areas have a tendency to decrease in size to go into an energetically more favorable state. This "sintering effect" partly explains the difficulty of maintaining a microporous matrix for an extended period of time without some structural or chemical degradation. Moreover, as discussed in more detail below, the highest separation selectivities for gases achieved with a ceramic microporous membrane were obtained with amorphous $\mathrm{SiO}_{2}$ (de Vos and Verweij 1998). This material is not hydrothermally stable; under wet conditions, its microstructure degrades relatively quickly.

In 2008, the first member of a new class of silica-based hybrid membranes was demonstrated with superior hydrothermal stability while still offering high flux and reasonable separation selectivity (Castricum et al. 2008c). These membranes are based on the use of bridged silsesquioxane precursor molecules (OEt) ${ }_{3} \mathrm{Si}-\mathrm{R}-\mathrm{Si}$ $(\mathrm{OEt})_{3}$, and they are made by a solgel process. Several bridged groups $\mathrm{R}$ have already been used in hybrid silica membranes. In general they are linear aliphatic or aromatic bridges, e.g., alkylenes $-\mathrm{C}_{\mathrm{n}} \mathrm{H}_{2 \mathrm{n}^{-}}(n=1,2,3,6,8$, and 10), ethenylene $-\mathrm{C}_{2} \mathrm{H}_{2-}$, ethynylene $-\mathrm{C} \equiv \mathrm{C}$-, and the arylenes p-phenylene $-\mathrm{p}-\mathrm{C}_{6} \mathrm{H}_{4^{-}}$, and di-pphenylene $-\mathrm{p}-\mathrm{C}_{6} \mathrm{H}_{4}-\mathrm{p}-\mathrm{C}_{6} \mathrm{H}_{4}-$ (Castricum et al. 2011; Paradis et al. 2013; $\mathrm{Xu}$ et al. 2014). More recently, a precursor with a malonamide-functional bridge and a triazine-functional precursor have been reported (Besselink et al. 2015; Ibrahim et al. 2014b). 
The fundamental difference between this new class of hybrid membranes and the known silica (de Vos and Verweij 1998) and organically modified silica (R'-Si $\equiv$ ) (Campaniello et al. 2004; de Vos et al. 1999) membranes is the fact that hybrid membrane networks contain both ceramic $\equiv \mathrm{Si}-\mathrm{O}-\mathrm{Si} \equiv$ bonds and (hydrolytically stable) $\equiv \mathrm{Si}-\mathrm{R}-\mathrm{Si} \equiv$ bonds, with an atomic-scale dispersion of both types of bonds. In contrast, silica and organically modified silicas based on precursors such as tetraethyl orthosilicate (TEOS, $\mathrm{Si}(\mathrm{OEt})_{4}$ ) and methyl-triethyl orthosilicate (MTES, $\left.\mathrm{CH}_{3}-\mathrm{Si}(\mathrm{OEt})_{3}\right)$ have a network consisting entirely on ceramic $\equiv \mathrm{Si}-\mathrm{O}-\mathrm{Si} \equiv$ bonds. The mechanical properties of silica and organically modified silicas with only terminal organic groups are therefore typical for ceramic materials. In contrast, the mechanical properties of hybrids do not resemble ceramics, nor polymers, but are in between. Hybrid silicas have a considerably higher toughness than silica, and a lower E-modulus (Dubois et al. 2007), making them more resistant to mechanical and thermal stresses in the material during formation and operation.

This chapter presents a short overview of the state of the art in these hybrid organosilica membranes for molecular separations. The discussion is limited to hybrid membranes, i.e., 3D-bonded microporous networks containing both $\equiv \mathrm{Si}-\mathrm{O}-\mathrm{Si} \equiv$ and $\equiv \mathrm{Si}-\mathrm{R}-\mathrm{Si} \equiv$ groups. For a review of the solgel processing of amorphous microporous silica and organically modified silica membranes, the reader is referred to other sources (Chapman et al. 2008; Lin et al. 2002; Lu et al. 2007). The next section contains a brief outline of the development of ceramic membranes over the past decades. The overview starts with the development of mesoporous ceramic membranes with a Knudsen-type separation mechanism in the 1980 s, followed by the developments in microporous silica membrane processing, and ends with the introduction of hybrid organosilica membranes in 2008. An overview of the progress, state of the art, and application of hybrid organosilica membranes in pervaporation and gas separation since 2008 is given in section "Hybrid Organosilica Membranes for Gas Separation and Pervaporation." Section "Sol-Gel Processing of Hybrid Organosilica Materials" describes the solgel chemistry of these bridged solgel precursors from single molecules up to the thermally consolidated microporous state. Details of the solgel processing of supported hybrid organosilica membranes, including methods to determine their pore size distributions and presence of larger defects in the layer, are presented in section "Supported Membrane Preparation and Determination of Pore Size Distribution."

\section{Historical Outline of Microporous Ceramic Membrane Development}

The first solgel-derived ceramic membranes for the separation of gases were supported mesoporous $\gamma$-aluminas. When properly processed, this phase has a high porosity and narrow pore size distribution. The solgel process for $\gamma$-alumina films and membranes was developed in the 1980s (Keizer et al. 1988; Leenaars et al. 1984; Uhlhorn et al. 1989). These membranes typically have pore diameters of 
4-10 $\mathrm{nm}$ and are defect-free at a film thickness of a few micrometers. This first generation of membranes demonstrated that gases can be separated via some molecular selection mechanism exploiting a rigid but highly porous ceramic framework with a relatively high permeability for small molecules in comparison with zeolites and polymers. This is of large interest from a technological point of view, since the high thermal and chemical stability of ceramics make them a promising class of materials for long-term large-scale application at elevated temperatures, pressures, and extreme $\mathrm{pH}$ conditions in the chemical industry.

Mesoporous membranes such as $\gamma$-alumina are, by IUPAC definition, membranes with a pore diameter between 2 and $50 \mathrm{~nm}$. Under normal temperature and pressure conditions, molecules that diffuse through a 3D mesopore structure will come into contact more frequently with the pore walls than with other permeating species. Between collisions with the wall, the transported molecules act as gas-phase species, which is why the transport rate of species under these conditions is determined by the molecular gas-phase velocity. This type of diffusion is called Knudsen diffusion (Keizer et al. 1988). For ideal gases, the gas-phase velocity $v$ scales with the inverse of the root of molar mass $M, v \sim 1 / \sqrt{ } M$. For a mixture of gases with molecular masses $M_{1}$ and $M_{2}$ and $M_{1}>M_{2}$, the intrinsic selectivity of the membrane for this mixture will be $\sqrt{ }\left(M_{1} / M_{2}\right)$. So even when the molecular masses differ by as much as 2 orders of magnitude, a separation factor of only 10 will be accomplished.

To achieve higher permselectivities, it is necessary to exploit an alternative, more selective sieving mechanism. Such a mechanism requires a stronger interplay between the permeating species and the pore matrix, in order to promote or hinder the transport in a more species-selective manner. Hence, the use of a microporous structure with pore diameter $<<2 \mathrm{~nm}$, in which a permeating molecule continuously senses the pore wall owing to its close proximity, is a logical step.

In principle, various metal oxides could be used for that purpose. The amorphous silica phase is particularly useful since its microstructure can be tuned in the solgel process to form a matrix that contains only micropores $<<1 \mathrm{~nm}$. Since most small molecules have kinetic diameters slightly below this value, careful tuning of the pore size distribution should allow to tailor-make matrices for the separation of specific mixtures of gases or liquids. A second advantage of silica is the absence of any tendency to crystallize at the preparation and operating temperatures. Microporous silica membranes were developed in the late 1980s and 1990s (de Vos and Verweij 1998; Elferink et al. 1996; Uhlhorn et al. 1992). Made by acid-catalyzed solgel processing of tetra-(m)ethyl-orthosilicate (TEOS or TMOS), they were shown to have an extremely high selectivity for the separation of small industrial gases with a kinetic diameter $<0.4 \mathrm{~nm}$, e.g., $\mathrm{H}_{2}, \mathrm{CO}, \mathrm{CO}_{2}, \mathrm{CH}_{4}, \mathrm{~N}_{2}$, and $\mathrm{O}_{2}$. For example, for binary mixtures $\mathrm{H}_{2} / \mathrm{CO}_{2}, \mathrm{H}_{2} / \mathrm{N}_{2}, \mathrm{H}_{2} / \mathrm{CH}_{4}$, and $\mathrm{CO}_{2} / \mathrm{CH}_{4}$, selectivities can be as high as 100, >170, >5000, and $>100$, respectively (de Vos and Verweij 1998). The selection mechanism of microporous silica is primarily based on size-based sieving, i.e., smaller molecules travel more easily through the porous matrix than larger ones. An advantage of employing the solgel process to make membranes is that this route leads to membranes with a high selectivity and high permeability. Silica membranes may also be made by the chemical vapor deposition (CVD) method, and while such 
membranes show even enhanced selectivity, the permeability may be one or more orders of magnitude lower, i.e., CVD leads to a denser but often more selective network structure than solgel-processed silica membranes. In terms of product yield, the higher permeability of solgel membranes outweighs their lower selectivity. A discussion of CVD-derived microporous silica membranes is beyond the scope of this chapter, and the reader is referred to other studies (Ockwig and Nenoff 2007; Prabhu and Oyama 2000).

Although microporous silica membranes show a high chemical and thermal stability under dry conditions, they quickly lose much of their excellent performance at temperatures as low as $60{ }^{\circ} \mathrm{C}$ when water is present. The reason is the hydrolytically labile $\equiv \mathrm{Si}-\mathrm{O}-\mathrm{Si} \equiv$ bond between silicon atoms that break and form two terminal $\equiv \mathrm{Si}-\mathrm{OH}$ groups upon reaction with water (Fotou et al. 1995). Other amorphous metal oxides like titania and zirconia have also been reported as microporous membranes, but their pore sizes are $>0.5 \mathrm{~nm}$ so that they do not exhibit the same high selectivities in gas permeation and liquid dehydration as microporous silica (Sekulic et al. 2004; Spijksma et al. 2006). Moreover, these amorphous phases have a limited (hydro)thermal stability as they present metastable states. Crystallization occurs easily, leading to grain enlargement, larger pores, and consequently loss of selectivity (Sekulic et al. 2004).

An alternative strategy to increase the hydrothermal stability of silica is by co-doping metal oxides to form hydrolytically more stable $\equiv$ Si-O-M $\equiv$ bonds, where $\mathrm{M}=\mathrm{Nb}, \mathrm{Fe}, \mathrm{Ti}, \mathrm{Zr}, \mathrm{Al}, \mathrm{Mg}$, etc. (Boffa et al. 2013; Ockwig and Nenoff 2007), and while improvements have been reported, none of these studies demonstrated convincingly that complete stabilization of the silica network under humid conditions is possible.

A third strategy to improve the hydrothermal stability is to replace one of the hydrolytically unstable groups by incorporation of terminal alkyl groups or fluorinated hydrocarbon groups covalently attached to a Si center (de Vos et al. 1999; Wei et al. 2008). The idea is that the hydrophobic nature of the carbon-based terminal group shields the remaining silica network from penetration of water, while some of the hydrolytically unstable $\equiv \mathrm{Si}-\mathrm{O}$ bonds are replaced by hydrolytically stable Si-C bonds. Unfortunately, the cross-link density of the silica network decreases as a result, and this leads to a reduction of the permselectivity of the membrane in comparison with amorphous $\mathrm{SiO}_{2}$. While amorphous $\mathrm{SiO}_{2}$ calcined at $400{ }^{\circ} \mathrm{C}$ or $600{ }^{\circ} \mathrm{C}$ is virtually impermeable to molecules $>0.4 \mathrm{~nm}$ (de Vos and Verweij 1998), microporous methylated silica made from TEOS and MTES also shows a noticeable flux for species larger than $0.4 \mathrm{~nm}$ (de Vos et al. 1999). The separation factor of $\mathrm{H}_{2} /$ $\mathrm{CH}_{4}$ in methylated silica was 25 and that of $\mathrm{H}_{2} / \mathrm{CO}_{2}$ was $10-15$. Hence, the separation selectivities for similar separations are lower for the methylated silica membrane. They are however still higher than is possible with a Knudsen separation mechanism, demonstrating the microporous nature of these membranes. Its hydrothermal stability in the pervaporation of water from water-butanol mixtures at $115^{\circ} \mathrm{C}$ was also considerably improved in comparison with silica (Campaniello et al. 2004), but for actual application in industrial processes, still a higher stability was required. 


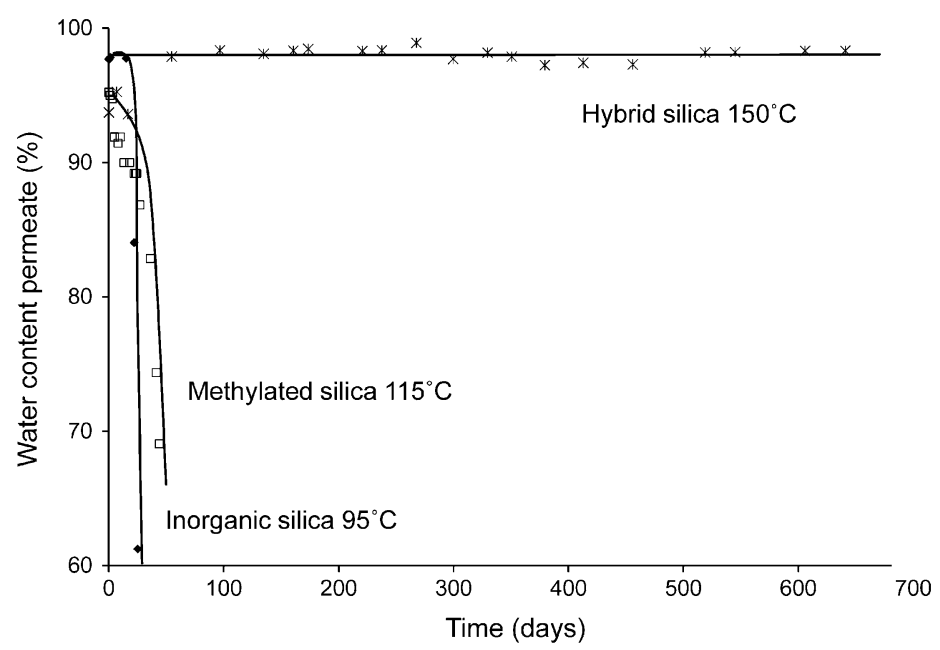

Fig. 1 Water content in permeate for a hybrid silica membrane operating continuously at $150{ }^{\circ} \mathrm{C}$ in pervaporation of $5 \mathrm{wt} \%$ water-95 $\mathrm{wt} \% n$-butanol. Selectivity is compared with methylated and inorganic silica membranes (Reproduced from Castricum et al. (2008c) with permission from The Royal Society of Chemistry)

The introduction of hydrolytically stable organic bridging $\equiv \mathrm{Si}_{-} \mathrm{C}_{2} \mathrm{H}_{4}-\mathrm{Si} \equiv$ groups in the silica network structure in 2008 resulted in a microporous membrane with good separation properties for the removal of water from $n$-butanol and other solvents (Castricum et al. 2008c, d). The membrane shows long-term hydrothermal stability under operating conditions at the industrially relevant temperature of $150{ }^{\circ} \mathrm{C}$. See Fig. 1. The first membrane, which was made from a mixture of bis (triethoxy-silyl)ethane (BTESE) and MTES, was taken off-stream after 700 days for examination, although its lifetime had not expired by then.

The exceptional stability of this class of hybrid membranes, which will be referred to as hybrid organosilica membranes in the remainder of this chapter, has been attributed to three factors (Castricum et al. 2008d): (1) the presence of hydrolytically stable $\mathrm{Si}-\mathrm{C}$ bonds and the hydrophobicity introduced in the membrane matrix due to the presence of $-\mathrm{C}_{2} \mathrm{H}_{4^{-}}$(or other organic) bridging groups, (2) the improved mechanical properties of the thin-film membrane resulting from the presence of flexible $\equiv \mathrm{Si}_{-} \mathrm{C}_{\mathrm{x}} \mathrm{H}_{\mathrm{y}}-\mathrm{Si} \equiv$ segments in the chains that can withstand thermal and mechanical stresses more easily than inorganic thin-film membranes, and (3) the solubility, molecular weight, and number of anchoring groups of the BTESE precursor. While it is known that in the presence of water, $\mathrm{SiO}_{4}$ units dissolve easily from a membrane surface, diffuse away, and then reprecipitate somewhere else, the chance that the same happens with a BTESE-derived unit is much smaller. First of all, the solubility of BTESE units in water is smaller than for species like $\mathrm{SiO}_{4}$ and secondly because $6 \equiv \mathrm{Si}-\mathrm{O}-\mathrm{Si} \equiv$ groups instead of 3 (MTES) or 4 (TEOS) have to be hydrolyzed before the monomer is able to go into solution (Castricum et al. 2008d). The statistical chance that this happens is much lower. The 
development of these very stable hybrid (organo)silica membranes has led to renewed interest in molecular separations of gases and liquids under harsh conditions and to the release of a commercial product named $\mathrm{HybSi}^{\circledR}$ (Agirre et al. 2011; van Veen et al. 2011).

\section{Solgel Processing of Hybrid Organosilica Materials}

The solgel chemistry of silicon alkoxides, in particular TMOS and TEOS, has been studied in detail and is described in various well-known works (Brinker and Scherer 1990). The hydrolysis reaction $=\mathrm{Si}-\mathrm{OR}+\mathrm{H}_{2} \mathrm{O} \rightarrow=\mathrm{Si}-\mathrm{OH}+\mathrm{ROH}$ and condensation reaction $2=\mathrm{Si}-\mathrm{OH} \rightarrow=\mathrm{Si}-\mathrm{O}-\mathrm{Si}=+\mathrm{H}_{2} \mathrm{O}$ occur under relatively mild conditions, typically carried out in nonaqueous solvents such as alcohols. The reactions are kinetically controlled, so that the evolution of morphology of silica nanostructures can be controlled via precursor concentration and type and concentration of Brönsted acid/base catalyst. Acid-catalyzed sols are needed to make microporous membranes without (large) mesopores, i.e., sols consisting of slightly branched oligomeric chains of condensed silicon alkoxide monomers (Brinker and Scherer 1990).

Such branched polymeric sol particles are able to interpenetrate each other during the film drying process, so that a relatively dense and homogeneous matrix without large pores is formed (Brinker and Scherer 1990). Since the microporous layer is made by coating onto a porous substrate, the sol size needs to be at least as large as the size of the pore of the underlying mesoporous substrate. Otherwise penetration of the sol into the substrate would occur, leading to a nonporous highly resistive interface.

\section{Solgel Chemistry of Bridged Silsesquioxanes}

The solgel chemistry of bridged silsesquioxanes is similar to that of simple silicon alkoxides (Brinker and Scherer 1990), although there are some notable differences. Typical precursors to bridged polysilsesquioxanes are monomers with six functional groups. Many of these monomers polymerize rapidly in the presence of water and catalyst to form gels, even as very dilute solutions (ca. $0.1 \mathrm{M}$ ), both under acidic and basic conditions. Silicon alkoxide precursors with only three or four functional groups such as TEOS and MTES need much higher degree of condensation (conversion) to reach the gelation point.

A special feature of bridged silsesquioxanes is the tendency of some precursors to cyclic condensations (Loy et al. 1996). The flexible alkylene-bridging group provides opportunity for intramolecular reactions (Shea and Loy 2001). Also cyclic dimerization, yielding condensed entities that are not very reactive and that may not become incorporated into a larger network structure, is formed in some cases. For microporous membranes, this is of importance, since these oligomers do not form structures of sufficient size to avoid penetration into a mesoporous substrate during 


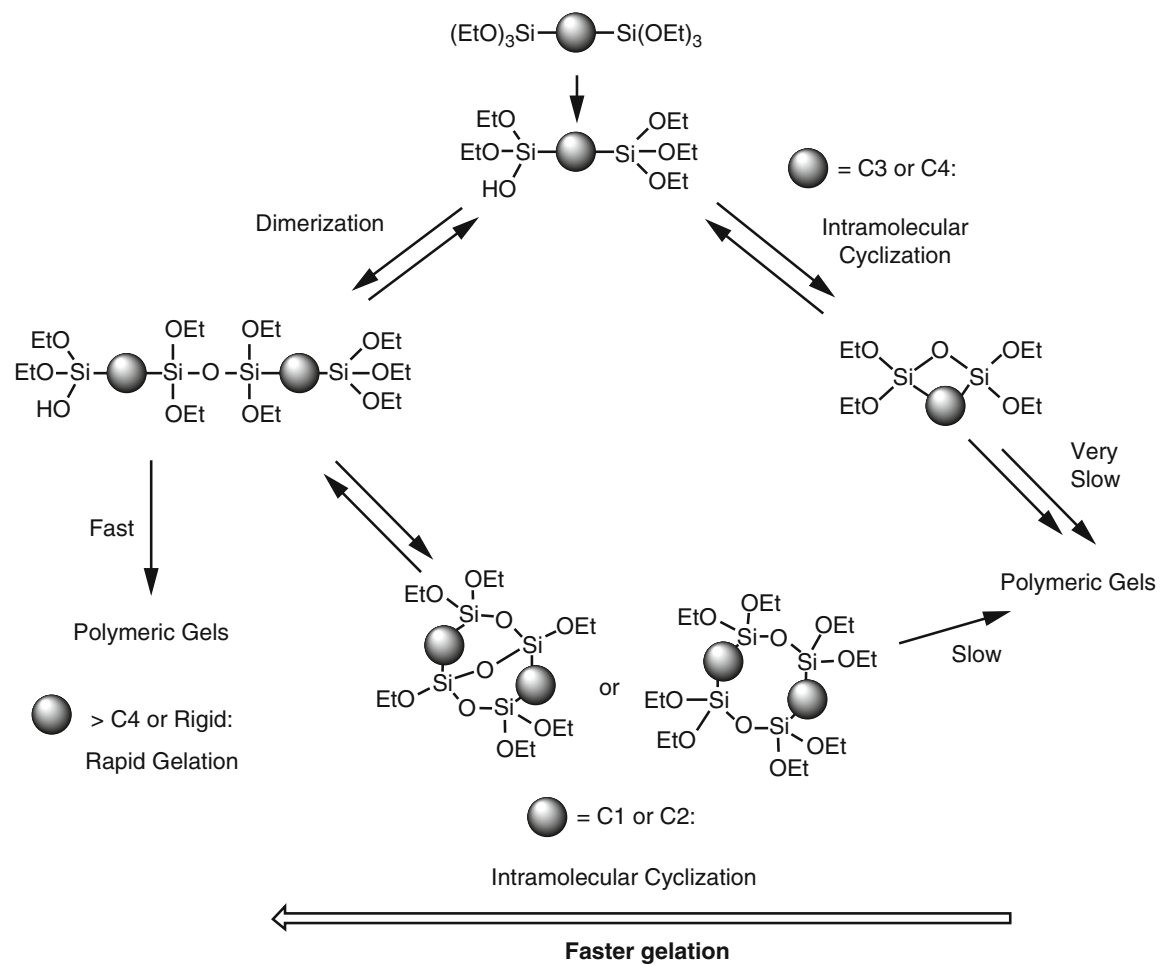

Fig. 2 Condensation pathways of bridged silsesquioxane precursors under acid-catalyzed conditions depending on length and flexibility of the bridging chains (Reprinted with permission from (Shea and Loy 2001). Copyright 2001 American Chemical Society)

the film coating step of the membrane preparation process. Shea and Loy distinguish between three types of bridged monomers, based on differences in chain length and rigidity of the bridging group (see Fig. 2):

1. Monomers with bridging groups that are either short and stiff, e.g., arylene bridges, or long and flexible alkylenes, e.g., $-\mathrm{C}_{6} \mathrm{H}_{12^{-}},-\mathrm{C}_{10} \mathrm{H}_{20^{-}}$, etc. These monomers do not undergo the mentioned cyclization reactions and can therefore gel very rapidly because of fast network formation.

2. Monomers with $\mathrm{C}_{1 \text { - }}$ and $\mathrm{C}_{2}$-bridging groups, e.g., $-\mathrm{CH}_{2}$ - and $-\mathrm{C}_{2} \mathrm{H}_{4}$, , but also vinylidene- and cis-ethenylene-bridged monomers. Their gel times are significantly longer than those of their longer-chain analogues. While both branched and linear hybrid oligomers have been observed, they also form several cyclic dimeric species. Bridged bicyclic species dominate the composition of the methylene-bridged oligomers.

3. Bridging groups with three or four bridging carbons, $\mathrm{C}_{3}$ and $\mathrm{C}_{4}$. Under standard acidic solgel conditions, these monomers do not gel even after months of storage. 
This is caused by fast and intramolecular condensation reactions, yielding nonreactive cyclic species. The failure of these monomers to gel is due to the reduction in number of functional groups from six to four and the intrinsic lower reactivity of the cyclic products toward subsequent condensation reactions.

The first steps in these hydrolysis/condensation processes are typically monitored using ${ }^{29} \mathrm{Si}$ nuclear magnetic resonance (NMR) and/or Fourier transform infrared (FTIR) spectroscopy. In the first studies on hybrid organosilica membranes based on BTESE, it was attempted to avoid such intramolecularly condensed cyclic carbosiloxanes by co-condensation with other species (Castricum et al. 2008c, d). BTESE was mixed with MTES in a 1:1 molar ratio. While MTES hydrolyzes faster than TEOS or BTESE, with hydrolysis rates of $1.2 \times 10^{-3}, 0.11 \times 10^{-3}$, and $0.42 \times$ $10^{-3} \mathrm{OH} / \mathrm{Si} \mathrm{s}^{-1}$ at $273 \mathrm{~K}$, respectively, the rates and degrees of condensation under comparable reaction conditions are relatively similar (Castricum et al. 2008b). Hence, mixing of precursors should lead to a substantial degree of co-condensation of dissimilar precursor types. In this way, the degree of autocondensation can be minimized (Castricum et al. 2008d). In later studies, hybrid organosilica membranes were mostly prepared from a single type of alkoxide precursor such as BTESE or BTESM (Castricum et al. 2011; Kreiter et al. 2009; van Veen et al. 2011).

The atomic-scale incorporation of transition metals into hybrid organosilica matrices is possible but requires substantial reduction of their high reactivity. A well-known strategy is to form complexes with strongly coordinating ligands prior to their reaction with silicon-based precursors. The use of acetylacetone to reduce the reactivity of $\mathrm{Nb}(\mathrm{OEt})_{5}$ prior to its reaction with BTESE $(\mathrm{Nb}: \mathrm{Si}=1: 4)$ yielded a large concentration of heterolinkages Si-O-Nb in the final material (Besselink et al. 2014). The distribution of oxygen among $\mathrm{Si}-\mathrm{O}-\mathrm{Si}$, Si-O-Nb, and $\mathrm{Nb}-\mathrm{O}-\mathrm{Nb}$ bonds was determined using ${ }^{17} \mathrm{O}$ NMR and was close to a statistical distribution. Other complexing agents were less effective.

\section{Structure Evolution in Sols and Thin Films}

The branched oligomeric nanostructures that form during condensation can be considered as entities with a dimensionality $D_{\mathrm{i}}$ larger than one (unbranched one-dimensional chain) and three (dense sphere). The relationship between their mass $m$, radius of gyration $R_{\mathrm{g}}$, and dimensionality $D_{\mathrm{i}}$ can be generalized as: (Glatter and Kratky 1982)

$$
m \sim\left(R_{\mathrm{g}}\right)^{D_{\mathrm{i}}}
$$

The gyration radius is obtained by small-angle $\mathrm{x}$-ray scattering (SAXS) experiments on sols using the universal Guinier relationship (Glatter and Kratky 1982): 


$$
\lim _{q \rightarrow 0} I(q) \sim \exp \left(-R_{\mathrm{g}}^{2} q^{2} / 3\right)
$$

Here $I(q)$ is the scattering intensity as a function of scattering vector $q\left(\mathrm{~nm}^{-1}\right)$. The parameter $D_{\mathrm{i}}$ is essentially a measure of the internal structure of a sol; it quantifies the degree of branching. Larger values of $D_{\mathrm{i}}$ refer to more highly branched sols. In a limited $q$-range, the SAXS curves of silica-based sols show a linear relationship between $\log I$ and $\log q$, i.e.,

$$
I(q) \sim q^{D_{\mathrm{i}}}
$$

When $D_{\mathrm{i}}$ is too small, the branched oligomers cannot interpenetrate and become entangled during drying because of the absence of branches. On the other hand, interpenetration of branches also becomes impossible when $D_{\mathrm{i}}>>1.6$, because their density would be too high for neighboring particles to interpenetrate. Sols with much smaller gyration radii than the pore size of the mesoporous layer (e.g., $\gamma-\mathrm{Al}_{2} \mathrm{O}_{3}$ with a pore diameter of $6 \mathrm{~nm}$ ) will be sucked into that layer by capillary force and form a dense and resistive membrane, while sols with too high hydrodynamic diameter $\left(R_{\mathrm{g}}\right.$ $>>10 \mathrm{~nm}$ ) form thicker films with a fraction of large pores or a tendency to macroscopic cracking after drying (Castricum et al. 2008d). Acid-catalyzed organosilica sols suitable for membrane formation usually have a radius of gyration $R_{\mathrm{g}}<10 \mathrm{~nm}$ and $D_{\mathrm{i}}=1.2-1.6$.

The dominant growth mechanism under most typical solgel preparation conditions is diffusion-limited cluster aggregation (DLCA), which ultimately results in nanostructures with $D_{\mathrm{i}}=1.8-1.9$ (Boffa et al. 2009; Lin et al. 1989; Maene et al. 1998). In DLCA the approach of particles is controlled by Brownian transport, and the rate of reaction is much higher than the rate of transport. A study on sols with $-\mathrm{CH}_{2^{-}},-\mathrm{C}_{2} \mathrm{H}_{4}-,-\mathrm{C}_{8} \mathrm{H}_{16^{-}}$, p-phenylene (-p- $\left.\mathrm{C}_{6} \mathrm{H}_{4}-\right)$, and di-p-phenylene (-p- $\mathrm{C}_{6} \mathrm{H}_{4}-\mathrm{p}$ $\left.\mathrm{C}_{6} \mathrm{H}_{4^{-}}\right)$bridging groups showed that the values of $D_{\mathrm{i}}$ are similar $\left(D_{\mathrm{i}}=1.5-1.6\right)$ when the radii of gyration are similar $\left(R_{\mathrm{g}}=1.5-2.3 \mathrm{~nm}\right)$, even though the reactivity of the precursors varies (Castricum et al. 2011). Defect-free membranes with molecular sieving properties could be formed from all five sols.

The acid concentration also has a profound influence on the formation of the pore structure of hybrid organosilicas. The evolution of nanostructure is very different depending on the $\left[\mathrm{H}^{+}\right] /[\mathrm{Si}]$ ratio (Castricum et al. 2014). In situ SAXS experiments on drying BTESE films with $[\mathrm{Si}]=0.9 \mathrm{M},\left[\mathrm{H}_{2} \mathrm{O}\right] /[\mathrm{Si}]=1$, and $\left[\mathrm{H}^{+}\right] /[\mathrm{Si}]=0.01$ at room temperature showed a decreasing scattering intensity, while $D_{\mathrm{i}}$ dropped to zero after $4000 \mathrm{~s}$. This implies the formation of a homogeneous film without pores visible on the length scale of the scattering experiment $(\sim 0.5 \mathrm{~nm}$ and larger). When the $\left[\mathrm{H}^{+}\right] /[\mathrm{Si}]$ ratio was increased to 0.1 , a smaller decrease in scattering intensity was observed upon drying. $D_{\mathrm{i}}$ decreased from 1.2 to $\sim 0.4$ in the final as-dried film after $4000 \mathrm{~s}$. This value is illustrative for a densifying film with a final "fractal-like" pore structure. A third film with $\left[\mathrm{H}^{+}\right] /[\mathrm{Si}]=1$ showed complex drying behavior. It developed initially in a similar way as the films with lower acid ratio, but then $D_{\mathrm{i}}$ increased to 2.15 after $4500 \mathrm{~s}$, followed by a gradual decrease to a final value of 
$\sim 1.5$. While the detailed interpretation of this process is complicated, the final decrease suggests a slow densification process, however less than in the other two cases. What this study illustrates is that the presence of $\mathrm{H}^{+}$is necessary to construct and/or maintain a porous network structure in the drying film (gel) during solvent evaporation. The naturally occurring capillary forces and compressive stresses during drying and film shrinkage promote the densification of the hybrid silica network into a dense structure with small or no pores, but these forces seem to be counteracted at high acid concentrations. Possibly the network is also strengthened by ongoing condensation catalyzed by $\mathrm{H}^{+}$and/or by the positive charge on the polymeric colloidal network that may somehow stabilize it. Thermal processing of these BTESE solgels in $\mathrm{N}_{2}$ atmosphere at $523 \mathrm{~K}$ yielded powders with $\mathrm{N}_{2}$ BET surface areas of 0,632 , and $970 \mathrm{~m}^{2} / \mathrm{g}$, respectively, and corresponding pore sizes $<$ $0.3\left(\mathrm{~N}_{2}\right.$ size), 1.5, and $2.7 \mathrm{~nm}$ (Castricum et al. 2014). Hence, the presence of $\mathrm{H}^{+}$ during reaction and film drying leads to a more open network with larger pores. This study clearly demonstrates the importance of the $\mathrm{H}^{+}$concentration to tailor the pore size of a hybrid silica membrane. Interestingly, the pore structure can be adapted in this way, i.e., by adjustment of the acid-to-Si ratio before the onset of physical drying, while the original rheological properties needed for film coating are retained.

\section{Pore Structure in Thermally Consolidated Materials}

The presence of organic groups in the hybrid matrices after thermal treatment can be determined by Fourier transform infrared (FTIR) spectroscopy. The symmetric and asymmetric stretching of the organic groups can be found in the high-frequency range, i.e., $2800-3000 \mathrm{~cm}^{-1}$ for the alkylene systems and $2950-3100 \mathrm{~cm}^{-1}$ for the aromatic systems. Ethylene- and octylene-bridged materials show a broad band at 2800-2950 $\mathrm{cm}^{-1}$, while the $-\mathrm{CH}_{2}$ - bridged system has an additional pronounced peak at $2975 \mathrm{~cm}^{-1}$, at similar position as the terminal methyl group from MTES.

The pore structure of hybrid organosilica after thermal treatment differs significantly from the pore structure of microporous $\mathrm{SiO}_{2}$. Molecular dynamic (MD) simulations of $-\mathrm{C}_{2} \mathrm{H}_{4}$ - and $-\mathrm{C}_{2} \mathrm{H}_{2}$ - bridged systems suggest that the pore size distribution of hybrids is slightly shifted toward larger pore sizes than in $\mathrm{SiO}_{2}$ (Kanezashi et al. 2010; Shimoyama et al. 2013). Simulated pore size distributions of BTESE hybrid silica and $\mathrm{SiO}_{2}$ silica are shown in Fig. 3 (Chang et al. 2010, 2011). It is noted that the smallest gases and vapors relevant for separation with membrane process are $\mathrm{H}_{2} \mathrm{O}$ and $\mathrm{NH}_{3}$, both with a kinetic diameter $<0.2 \mathrm{~nm}$. Then come hydrogen $(0.29 \mathrm{~nm}), \mathrm{CO}_{2}, \mathrm{~N}_{2}, \mathrm{CO}$, and $\mathrm{CH}_{4}$, all with kinetic diameters below $0.38 \mathrm{~nm}$. As can be seen in the figure, the majority of hybrid pores has a pore size comparable to microporous $\mathrm{SiO}_{2}$, the most gas permselective solgel membrane known (de Vos and Verweij 1998). But a small fraction in the hybrid system has a pore diameter $>0.4 \mathrm{~nm}$. This larger pore size is related to the organic bridging groups that make the Si to Si distances, i.e., the branching points in the 3D network, larger. The presence of a small fraction of large pores also explains the comparatively low permselectivities obtained in the separation of elementary gases $\left(\mathrm{H}_{2}, \mathrm{CH}_{4}, \mathrm{CO}\right.$, 
Fig. 3 Simulated cavity size distribution of the pure silica and hybrid BTESE silica membranes (Reproduced from Chang et al. (2010) with permission of The Royal Society of Chemistry)

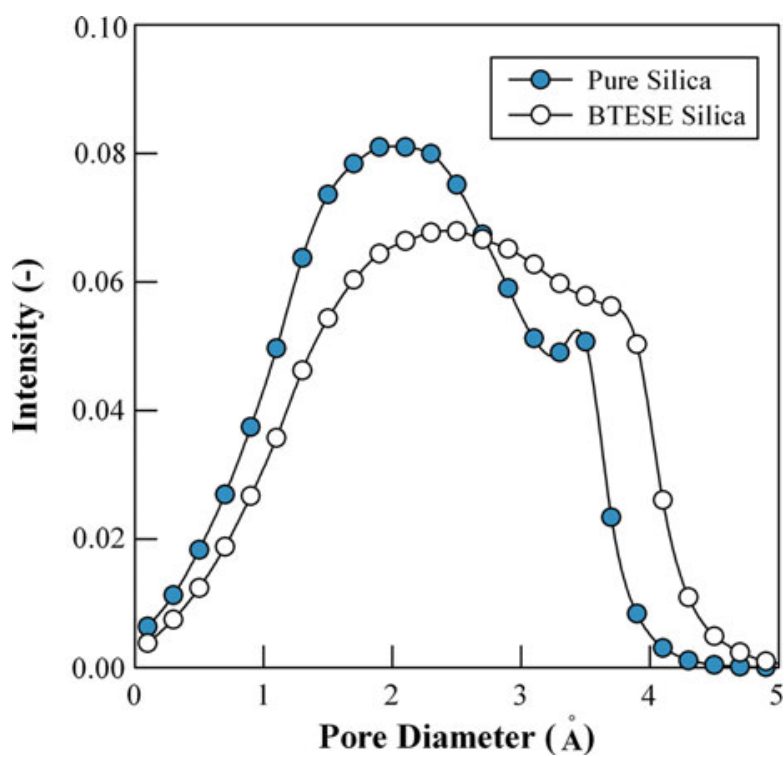

$\mathrm{CO}_{2}$ ), as discussed in more detail below. Much higher permselectivities can be accomplished for larger gases and vapors such as propene $(0.46 \mathrm{~nm})$-propane $(0.50 \mathrm{~nm})$ separation (Kanezashi et al. 2012a) and the separation of water from alcohols and other organic solvents, i.e., organic molecules with typical molecular diameters $>0.4 \mathrm{~nm}$.

Experimentally, BTESE powder made via a similar solgel process as BTESE membranes has an $\mathrm{N}_{2}$ BET surface area of $130-310 \mathrm{~m}^{2} / \mathrm{g}$ at $77 \mathrm{~K}$ and surface areas of 510-550 $\mathrm{m}^{2} / \mathrm{g}$ for ethene $\left(\mathrm{C}_{2} \mathrm{H}_{4}\right)$ and acetylene $\left(\mathrm{C}_{2} \mathrm{H}_{2}\right)$ at $273 \mathrm{~K}$ (Castricum et al. 2008a, 2011). The $\mathrm{N}_{2}$ adsorption isotherms are of type I and without hysteresis for both materials indicating full microporosity (Castricum et al. 2011). The size of $\mathrm{N}_{2}$ in BET experiments is assumed to be $0.30 \mathrm{~nm}$, while the size of $\mathrm{C}_{2} \mathrm{H}_{2}$ is only $0.24 \mathrm{~nm}$. So the latter value reflects the large fraction of ultra-small pores present in BTESE. BTESM has slightly smaller pores than BTESE owing to its shorter carbon bridge, i.e., almost no $\mathrm{N}_{2}$ adsorption at $77 \mathrm{~K}$, and somewhat lower values for $\mathrm{C}_{2} \mathrm{H}_{4}$ and $\mathrm{C}_{2} \mathrm{H}_{2}$ than BTESE.

The pore structure and pore connectivity can be strongly altered by co-condensation of other silicon alkoxide precursors such as MTES. Mixed BTESE-MTES powders (1:1 molar ratio) were found to have much smaller pores than BTESE. No adsorption of $\mathrm{N}_{2}$ occurred, while the adsorption of $\mathrm{C}_{2} \mathrm{H}_{2}$ indicated a surface area of $1340 \mathrm{~m}^{2} / \mathrm{g}$ (Castricum et al. 2008d). Moreover, the skeletal density of BTESE-MTES was $10 \%$ smaller than that of BTESE $(1.5 \mathrm{vs} .1 .7 \mathrm{~g} / \mathrm{mL}$; cf. dense $\mathrm{SiO}_{2}$ with density of $2.2 \mathrm{~g} / \mathrm{mL}$ ). Hence, the introduction of terminal methyl groups in the hybrid structure seems to promote the overall porosity and the fraction of ultrasmall $(<0.3 \mathrm{~nm})$ pores, while pore sizes $>0.3 \mathrm{~nm}$ are present but only accessible to $\mathrm{CO}_{2}\left(340 \mathrm{~m}^{2} / \mathrm{g}\right)$, not to $\mathrm{N}_{2}$. In comparison, MTES-derived methylated silica with the 
same overall $\mathrm{CH}_{\mathrm{x}}$ : $\mathrm{Si}$ ratio and microporous $\mathrm{SiO}_{2}$ silica both showed very little $\mathrm{N}_{2}$ adsorption (12 and $33 \mathrm{~m}^{2} / \mathrm{g}$, respectively), and their adsorption capacities for $\mathrm{C}_{2} \mathrm{H}_{2}$ were also smaller (211 and $261 \mathrm{~m}^{2} / \mathrm{g}$, respectively). So the average pore size of BTESE-MTES hybrid silica is smaller than that of MTES- and TEOS-derived silica. TEOS-MTES hybrids (1:1 molar ratio) even seem to have larger pores than the other systems, with a $\mathrm{N}_{2}$ BET surface area of at least $400 \mathrm{~m}^{2} / \mathrm{g}$.

Materials with longer organic bridging groups, i.e., octylene, phenylene, and biphenylene, also showed little or no uptake of $\mathrm{N}_{2}$, similar to BTESE and BTESM materials (Castricum et al. 2011). Despite their lengths, their pore sizes are not much larger than those of BTESM or BTESE. The skeletal densities are typically lower $(1.2-1.4 \mathrm{~g} / \mathrm{mL})$ than the densities of the shorter-chain analogues owing to their higher organic contents. It is noted that the helium $(0.20 \mathrm{~nm})$ pycnometry measurement used for skeletal density determination required long equilibration times for all hybrids, which is suggestive of very small pores and relatively poor interpore connectivity. The smallest micropores were found in the octylene-bridged sample. They were estimated to be even smaller than in BTESM. Also the lower adsorption potential for $\mathrm{CO}_{2}$ compared to all other investigated materials suggests that in the octylene-bridged material, gas adsorption is hindered, probably by the flexibility and/or conformation of the long alkylene bridge.

\section{Supported Membrane Preparation and Determination of Pore Size Distribution}

\section{Membrane Preparation}

The small pore size and relatively low porosity of hybrid organosilicas after thermal treatment finally results in a material that may have good intrinsic molecular sieving properties but that is also very resistive to transport of molecules. It is therefore imperative to keep the thickness of the separating layer minimal. For this reason, hybrid organosilica membranes are always used as thin films supported by a macroporous support structure that maintains mechanical integrity.

Organosilica sols are made by acid-catalyzed solgel processing of bridged silsesquioxane precursor molecules in an alcoholic solvent, usually ethanol. The bridged precursor is present at a concentration of 0.9-1 M. A typical reaction in ethanol involves $[\mathrm{Si}]=1.8-2.0 \mathrm{M}$ (two $\mathrm{Si}$ centers per bridged precursor), $\left[\mathrm{H}^{+}\right] /$ $[\mathrm{Si}]=0.1$, and $\left[\mathrm{H}_{2} \mathrm{O}\right] /[\mathrm{Si}]=2-3$. The $\mathrm{pH}$ of the resulting solution is $<1$ (Castricum et al. 2008b; Kreiter et al. 2011). To carry out the reaction, distilled water and nitric acid are added to dry ethanol, and the precursor is then added under vigorous stirring. The fast occurring hydrolysis reaction is very exothermic and may lead to a sudden initial temperature increase. Although many variations of the solgel process including room temperature processing are possible, the reaction is often carried out in a water bath set at $60{ }^{\circ} \mathrm{C}$ for $1-3 \mathrm{~h}$ under continuous stirring. The resulting stock sol can be stored for later use, although it should be kept in mind that the sol is not thermodynamically stable. These sols show noticeable growth at $-18{ }^{\circ} \mathrm{C}$ over a 


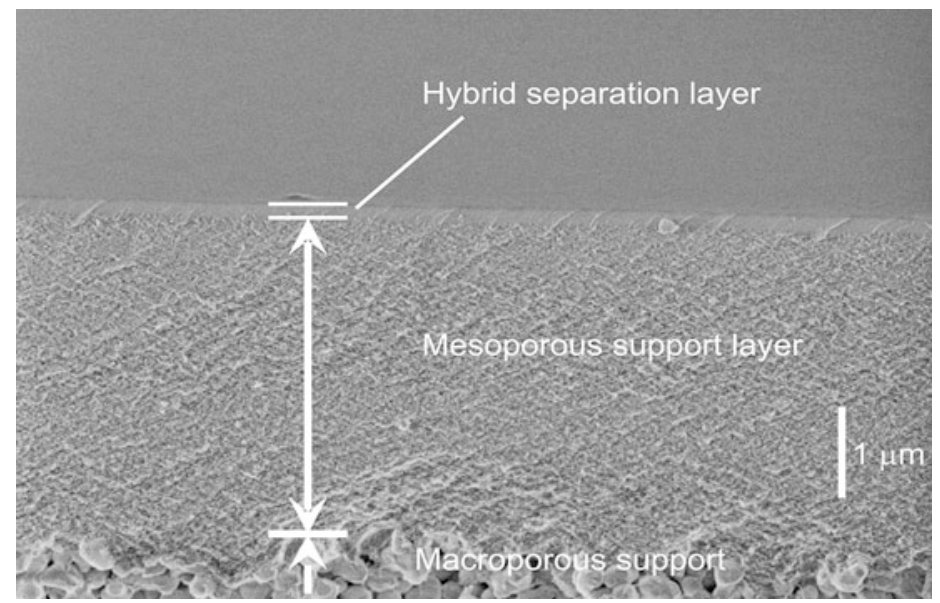

Fig. 4 Cross-sectional scanning electron micrograph of a hybrid composite membrane, showing the support, mesoporous cushion layer, and the selective hybrid silica top layer which has a thickness of $\sim 100 \mathrm{~nm}$

period of weeks, and we even noticed slow growth of hybrid silica sols at $-78{ }^{\circ} \mathrm{C}$ over a period of a few months. This sets a limit to the lifetime of the sol.

In most studies, the hybrid separation layer is dipcoated onto an $\alpha$-aluminasupported $\gamma$-alumina substrate with a single or double dipcoating step. Just before the hybrid silica sol is applied to form a membrane film, it is diluted with ethanol by a factor of 5-25 on the basis of volume to obtain a fast-drying film with good film formation properties and low (Newtonian) viscosity for the dipcoating process. After drying, the membranes are heat-treated in $\mathrm{N}_{2}$ or air to temperatures of $200-300{ }^{\circ} \mathrm{C}$. While short-bridged precursors such as BTESM seem to have a higher thermal stability up to $400{ }^{\circ} \mathrm{C}$ owing to the difficulty for oxidant $\left(\mathrm{O}_{2}\right)$ to enter the matrix and for reaction products such as $\mathrm{CO}, \mathrm{CO}_{2}$, etc. to leave the micropores, higher temperatures may lead to partial oxidation or degradation of the organic bridge and are generally avoided.

The macroporous $\alpha$-alumina support on which the hybrid film is deposited may be a disk or a tube. $\alpha$-Alumina supports have a thickness of about $1-2 \mathrm{~mm}$, a porosity of $30-35 \%$, and an average pore size of the order of $100 \mathrm{~nm}$. The pore size provides a rough estimate of the surface roughness. Since the final hybrid silica separation layer has a desired thickness of only $50-300 \mathrm{~nm}$, the coarse $\alpha$-alumina surface needs to be smoothened before the silica film can be applied. An intermediate $\gamma$-alumina layer of $1-3 \mu \mathrm{m}$ thickness is therefore deposited on the $\alpha$-alumina support. The layer is prepared from a boehmite $(\mathrm{AlOOH})$ sol by a dipcoating process. The $\gamma$-alumina phase combines high porosity ( $55 \%$ ) with a narrow mesoporous pore size distribution with a pore size of $3-6 \mathrm{~nm}$. The film is thermally treated at $400-600{ }^{\circ} \mathrm{C}$ in air and subsequently used as a substrate for hybrid silica membrane deposition. Figure 4 shows a BTESE-based membrane on a mesoporous $\gamma$-alumina layer that is coated on a coarse-grained macroporous $\alpha$-alumina support structure. 
Fig. 5 Gas permeance versus molecular kinetic diameter of gases for BTESE, BTESM, and inorganic silica (Tsuru et al. 2006) membranes at $200{ }^{\circ} \mathrm{C}$ (closed symbols, without heat treatment; open symbols, with heat treatment at $400{ }^{\circ} \mathrm{C}$ in air for $3 \mathrm{~h}$ ) (Reprinted with permission from Kanezashi et al. (2012a). Copyright 2012 American Chemical Society)

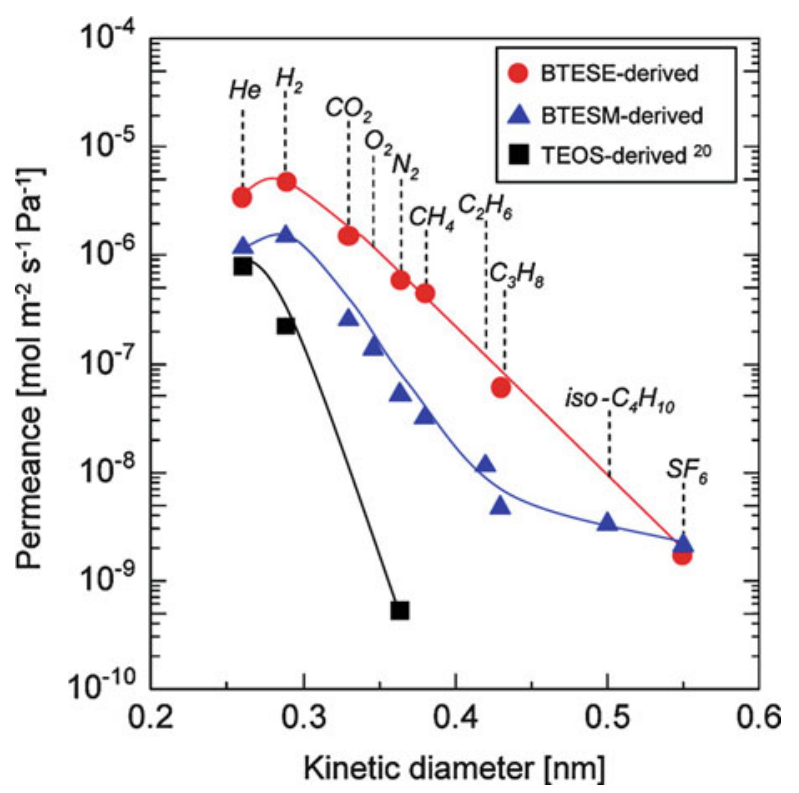

\section{Determination of Membrane Pore Size Distribution}

The most direct way to estimate or determine the pore size distribution of a microporous membrane is by performing single gas permeation measurements with a series of spherical probe molecules of known kinetic diameter. Ideally, the probes should be inert, i.e., have no or very weak (van der Waals) interactions with the pore wall, so that differences in permeability between different probes are solely determined by differences in their size. The permeability of these probe molecules as a function of their kinetic diameter provides a good estimate of the real pore size distribution of the membrane. Of course, many small molecules do not show ideal gas behavior. Simple gases such as $\mathrm{He}(0.20 \mathrm{~nm})$ and hydrogen $(0.29 \mathrm{~nm})$ are relatively inert at room temperature and above, but gases such as $\mathrm{CO}_{2}(0.33 \mathrm{~nm})$ can adsorb on the inner pore walls and even show surface diffusion rather than gas translation. Gases and vapors like $\mathrm{CH}_{4}(0.38 \mathrm{~nm}), \mathrm{C}_{2} \mathrm{H}_{6}(0.42 \mathrm{~nm}), \mathrm{i}-\mathrm{C}_{4} \mathrm{H}_{10}$ $(0.54 \mathrm{~nm})$, and $\mathrm{SF}_{6}(0.55 \mathrm{~nm})$ are commonly used (Kanezashi et al. 2014). The permeances of a BTESE, a BTESM, and a silica membrane as a function of kinetic diameter shown in Fig. 5 give a semiquantitative description of the (differences in) pore size distribution between the three systems. The hybrid membranes have a higher permeability than silica at any given kinetic diameter. The slope of the curves is a measure of the selectivity of the membranes for separation of mixtures of varying molecular sizes. The steeper slope of curve of the silica membrane indicates its higher permselectivity for small versus larger gases.

For pore size determination of mesoporous ( $>2 \mathrm{~nm}$ pores) membranes, the so-called permporometry technique is commonly used. Permporometry yields the pore size distribution of a (supported) membrane and provides an estimate of the 
concentration of defects in the layer. Essentially, the method is based on the use of the Kelvin equation for capillary condensation, $\ln \left(p / p_{0}\right)=-2 \gamma_{\mathrm{s}} V_{\mathrm{m}} / r_{\mathrm{K}} R T$, where $p / p_{0}$ is the relative pressure of some condensable vapor (e.g., cyclohexane), $\gamma_{\mathrm{s}}$ the surface tension of the condensed phase in the pore, $r_{\mathrm{K}}$ the so-called Kelvin radius, $V_{\mathrm{m}}$ the molar volume of the condensed phase, $R$ the gas constant, and $T$ the temperature (in $\mathrm{K}$ ). When a (meso)porous material is exposed to cyclohexane vapor with a set pressure $p / p_{0}$, all pores in the matrix with radius $<r_{\mathrm{K}}$ will be filled by liquid cyclohexane via capillary condensation. The gas flux of another, inert gas, will only occur through those pores that are still open, i.e., those that have a pore radius $>r_{\mathrm{K}}$ for a given $p / p_{0}$. Hence, the magnitude of the flux is a measure of the fraction of pores with radius $>r_{\mathrm{K}}$. By systematically varying $p / p_{0}$ of the condensable vapor, a pore size distribution can be extracted from the data. An inert gas flux at $p / p_{0}=1$ is an indication of the presence of large defects in the film. When the flux is zero under such conditions, the membrane is considered defect-free.

Unfortunately, the permporometry analysis is only valid under conditions where the Kelvin equation is valid, i.e., when the condensed (cyclohexane, water) phase can be considered as a continuous medium. Obviously, molecules in micropores do not form a continuous phase, and so the method is strictly speaking not applicable to microporous systems. But in practice, the Kelvin equation can still be extrapolated to obtain a rough measure of pore size, in particular for the qualitative comparison between similar systems. A method proposed and applied by Tsuru and coworkers is to determine at which relative pressure of the condensable gas the inert gas flux is only $50 \%$ of its value under dry conditions. Using the original Kelvin equation, an "effective Kelvin radius" (rather than a complete pore size distribution) is calculated from the data (Tsuru et al. 2003). Typically compounds like water and helium may be used in these experiments as condensable vapor and inert gas, respectively, because of their small kinetic diameters, which make them suitable for microporous matrices. The disadvantage of using water is that it is a rather polar molecule so that its condensation may be influenced by additional polar interactions not taken into account by the Kelvin equation.

\section{Hybrid Organosilica Membranes for Gas Separation and Pervaporation}

For a membrane to operate properly in a separation process, it needs to have three main properties:

1. Have a high permeability for the selected species in order to maximize the yield of the process

2. Serve as a selective barrier, excluding one or more components of a gas or liquid mixture, while allowing other selected species to pass

3. Have a long lifetime under the conditions of the separation process, i.e., the chemical and thermal stability should be sufficient, even under cleaning operations that typically make use of high $\mathrm{pH}$ chemicals 
The ability of a species $i$ to penetrate a membrane matrix is expressed in terms of the permeance $P_{\mathrm{i}}$. Its value is proportional to the concentration $c_{\mathrm{i}}$ and mobility $b_{\mathrm{i}}$ inside the microporous matrix, i.e., $P_{\mathrm{i}} \sim b_{\mathrm{i}} c_{\mathrm{i}}$. The permeance is essentially the ratio between flux $j_{\mathrm{i}}$ of species $i$ and applied driving force across the membrane:

$$
j_{\mathrm{i}}=-P_{\mathrm{i}}\left(\frac{\partial c_{\mathrm{i}}}{\partial x}\right)
$$

Here $\left(\partial c_{\mathrm{i}} / \partial x\right)$ refers to the concentration gradient of species $\mathrm{i}$, assuming a one-dimensional flux in $x$-direction. The membrane selectivity depends on variations in the ability of various species to travel through a membrane matrix. For a feed mixture of two gases with the same partial pressure, the so-called ideal permselectivity $S_{\mathrm{i}, \mathrm{j}}$ of a membrane is defined as:

$$
S_{\mathrm{i}, \mathrm{j}}=\left(P_{\mathrm{i}} / P_{\mathrm{j}}\right)
$$

The ideal permselectivity provides a rough indication of the separating capacity of a membrane material for a given mixture. Its value would have practical meaning if the respective fluxes of components $i$ and $j$ from a mixture would not be interfering with each other during their transport through the microporous matrix, as they do in reality. In practice, the individual permeances are determined via single-component gas flux measurements, and the ideal permselectivity is calculated from those data.

For a molecular sieving membrane, the pore size should be of similar size as the molecular diameter. It was already shown for gas transport in microporous TEOSderived membranes that the most important parameter determining the permeance of a species is the membrane pore size (de Vos et al. 1999; Nair et al. 2000). However, since the pore wall is very near to the molecule at all times, the inner pore chemistry also affects the transport of some or all passing species (Boffa et al. 2008; Sekulic et al. 2002). The membrane permselectivity is determined by the width of the pore size distribution; the narrower the pore size distribution, the more selective the membrane can be.

The chemical, thermal, and mechanical stabilities of a membrane are determined by both chemical composition and the $3 \mathrm{D}$ morphology of the microporous matrix. To achieve true microporosity, i.e., pore sizes $<<2 \mathrm{~nm}$, one typically needs an amorphous rather than a crystalline matrix. This is one of the main reasons why the most successful microporous ceramic membranes have been made using siliconbased building blocks; silica has virtually no tendency to crystallize. However, all silica-based solgel-derived microporous ceramics still have very high surface areas, in combination with pore walls with strong curvatures. Such a morphology is still intrinsically sensitive to pore size shrinkage or closure during thermal or chemical treatment, because that lowers the surface area considerably and with that the free energy of the matrix. Especially the smallest, permselective pores are also the most "sinter"-reactive ones. This is a general weakness of microporous matrices, and in combination with the limited chemical stability of the Si-O-Si bond, one can easily recognize what the main challenges are to stabilize microporous silica. 
As already discussed above, hybrid organosilica membranes have been demonstrated to be able to meet these challenges and form a 3D network structure that is both chemically and structurally stable even under many harsh industrial conditions. There are two types of separation processes in which molecular sieving membranes are commonly used, namely, pervaporation and gas separation.

\section{Pervaporation}

A pervaporation process is a process in which a liquid mixture is fed to the highpressure side of a membrane, while a (near-)vacuum is created at the low-pressure side, thus forming an as large as possible driving force over the membrane. The preferred component permeates into the membrane matrix from the high- to the low-pressure side, where it evaporates into the low-pressure atmosphere (pervaporation $=$ permeation + evaporation). The process is typically used for, but not limited to, the dehydration of industrial solvents and bioethanol. Microporous silica and methylated silica membranes were already shown to be effective in the pervaporation of solvent-water mixtures (Campaniello et al. 2004; Sekulic et al. 2002; ten Elshof et al. 2003), but these materials did not have sufficient hydrothermal stability under conditions typical in industrial processes.

The first report demonstrating that hybrid silica membranes are effective in alcohol dehydration was published in 2008 (Castricum et al. 2008c, d). The membrane was made from a 50:50 molar mixture of BTESE and MTES. It showed stable separation selectivity in the dehydration of $n$-butanol at $150{ }^{\circ} \mathrm{C}$ for more than 700 days, with an initial water flux $>10 \mathrm{~kg} \mathrm{~m}^{-2} \mathrm{~h}^{-1}$ that decreased only slowly to $\sim 50 \%$ of its initial value after 400 days of operation. TEOS-derived and methylated silica (MTES-TEOS) membranes degrade very quickly under such conditions due to poor hydrothermal stability (三Si-O-Si $\equiv+\mathrm{H}_{2} \mathrm{O} \rightarrow 2 \equiv \mathrm{Si}-\mathrm{OH}$ ) (see Fig. 1). The liquid feed contained $5 \mathrm{wt} \%$ water in $n$-butanol. The selectivity of the membrane process, expressed in terms of the separation factor $\alpha_{\mathrm{H} 2 \mathrm{O} / \mathrm{BuOH}}$, remained constant at $200-300$, i.e., the ratio of water $n$-butanol in the permeate stream was 300 times higher than in the feed. This means that the permeate stream contained $94 \mathrm{wt} \%$ water and $6 \mathrm{wt} \% n$-butanol. These selectivities were increased to $>99.5 \mathrm{wt} \%$ water in the permeate stream $\left(\alpha_{\mathrm{H} 2 \mathrm{O} / \mathrm{BuOH}}>2000\right)$ in later work (Kreiter et al. 2009). The selectivity was explained by the very small pore size of BTESE-MTES, as discussed in the previous section.

The first purely BTESE-based hybrid silica membrane has considerably larger pores $\left(\mathrm{C}_{2} \mathrm{H}_{2}\right.$ adsorption $\left.514-546 \mathrm{~m}^{2} / \mathrm{g} ; \mathrm{N}_{2} 131-311 \mathrm{~m}^{2} / \mathrm{g}\right)$ than the aforementioned compositions (Castricum et al. 2008a), and such a membrane would therefore be expected to be less selective. However, the separation factor in water $n$-butanol pervaporation $\left(\alpha_{\mathrm{H} 2 \mathrm{O} / \mathrm{BuOH}}=360-2700\right)$ was higher than that of BTESE-MTES, showing that besides the pore size, also other factors are important, e.g., pore connectivity and physicochemical interactions between permeating species and membrane matrix. BTESE membranes are resistant to aggressive aprotic solvents like $N$-methyl pyrrolidone (NMP), organic acids (Tsuru et al. 2012; van Veen 


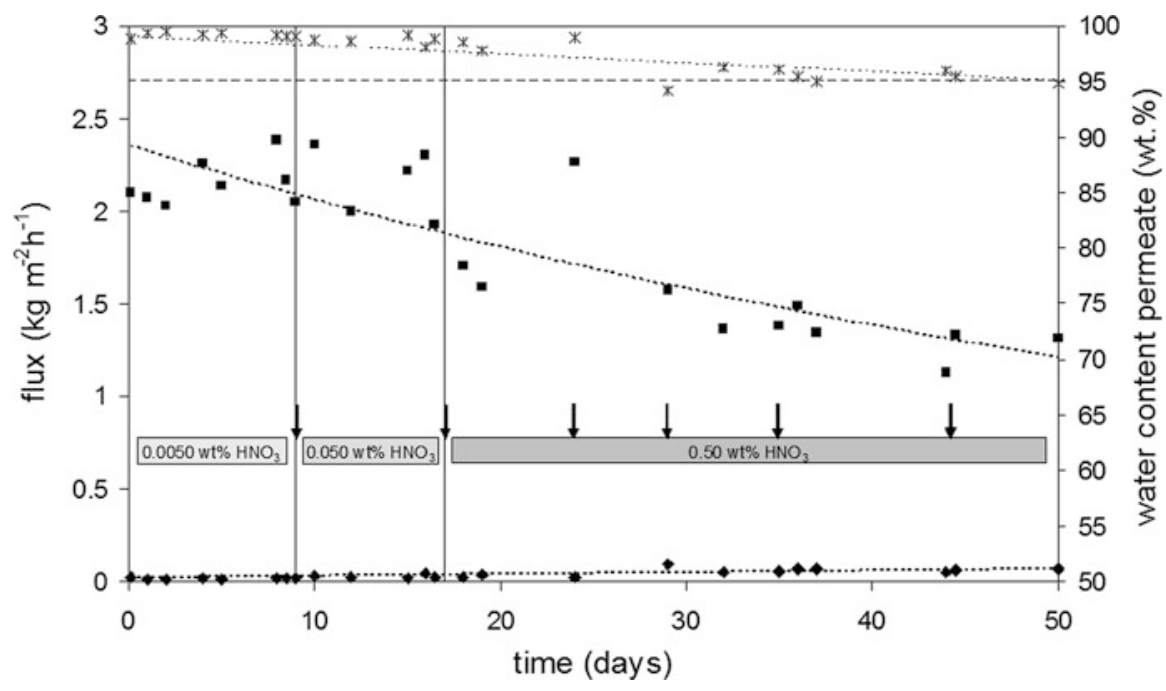

Fig. 6 Long-term separation (stars, water content of permeate; squares, water flux; diamonds, $n$ butanol flux) of a BTESE membrane from $5 \mathrm{wt} \%$ water $/ 95 \mathrm{wt} \% n$-butanol binary liquid at various $\mathrm{HNO}_{3}$ concentrations at $95{ }^{\circ} \mathrm{C}$. Arrows indicate moments at which additional $\mathrm{HNO}_{3}$ was added to keep the concentration constant (Reprinted from Castricum et al. (2008a) with permission from Elsevier)

et al. 2011), and $\mathrm{HNO}_{3}$ up to concentrations of $0.05 \mathrm{wt} \%$ in water-ethanol (pH 2.2) (van Veen et al. 2011). Higher concentrations of $\mathrm{HNO}_{3}$, or the use of stronger acids like methyl sulfonic acid, lead to fast deterioration of the membrane and complete loss of performance within a number of days (Castricum et al. 2008a; van Veen et al. 2011). See Fig. 6. The decreasing water flux and increasing butanol fluxes indicate that water-selective small micropores are disappearing at very low $\mathrm{pH}$, while the contribution of nonselective wider pores that are accessible to $n$-butanol is increasing.

Even higher water fluxes and higher separation factors were obtained when the $-\mathrm{C}_{2} \mathrm{H}_{4}$ - bridge (BTESE) was replaced by $-\mathrm{CH}_{2}$ - (BTESM) (Kreiter et al. 2009, 2011). The pore size of BTESM-derived membranes is smaller than BTESE but larger than BTESE-MTES (Kreiter et al. 2009). More importantly, the $\mathrm{CH}_{\mathrm{x}}$ :Si ratio of BTESM is only 0.5 , whereas that of BTESE and BTESE-MTES is 1 . This renders the BTESM membrane a more hydrophilic character than BTESE, MTES, or BTESE-MTES, and the high water flux may at least be partly attributed to that hydrophilic nature. The BTESM membrane also showed a surprising ability to separate water from lower alcohols, including the very difficult molecular separation of methanol and water (Kreiter et al. 2009; ten Elshof et al. 2003). A 5:95 wt/wt water-methanol mixture at the feed side of a BTESM membrane yielded a permeate stream containing 55:45 wt/wt water-methanol. This corresponds to a separation factor $\alpha_{\mathrm{H} 2 \mathrm{O}, \mathrm{MeOH}}=23$. This may seem low compared to values $>1000$ reported for water/ $n$-butanol (Gallego-Lizon et al. 2002; Sekulic et al. 2002), but methanol and 


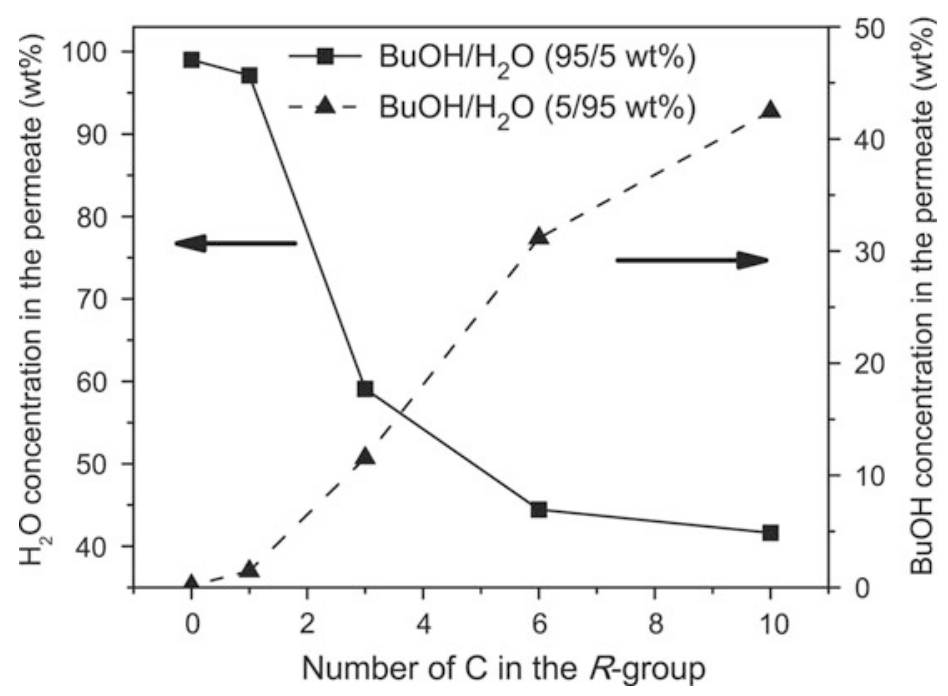

Fig. 7 Permeate concentration of $\mathrm{BuOH}$ and $\mathrm{H}_{2} \mathrm{O}$ as function of the number of $\mathrm{C}$ atoms in the terminal R group in pervaporation of $n$-butanol/water feed mixtures of $95 / 5$ and $5 / 95 \mathrm{wt} \%$. The feed concentrations were normalized to $5 \mathrm{wt} \%$ for direct comparison (Reprinted from Paradis et al. (2013) with permission from Elsevier)

water are very similar in size and comparable in their polarity and hydrogenbonding capability (ten Elshof et al. 2003). No other ceramic membranes are known that can separate water from methanol effectively while maintaining a high flux. For example, BTESE-MTES and BTESE are not selective for methanol-water, and even for ethanol-water, the BTESE-MTES membrane only has low selectivity $\left(\alpha_{\mathrm{H} 2 \mathrm{O}, \mathrm{EtOH}}=15\right)($ Kreiter et al. 2011). BTESM has separation factors $>150$ for ethanol, $i$-propanol, and $n$-butanol and shows higher water fluxes under otherwise similar conditions.

The degree of hydrophobicity of the membrane matrix can be controlled by adjusting the $\mathrm{CH}_{\mathrm{x}}$ :Si ratio. Obviously, longer aliphatic or aromatic bridges between the silicon centers may lead to membranes with a larger average pore size. Moreover, the network may become more flexible owing to the flexibility of longer chains, in particular long-chain alkylenes. A pervaporation study using hybrid silica membranes for water/n-butanol made from bridged silsesquioxane precursors with alkylene $-\mathrm{C}_{\mathrm{n}} \mathrm{H}_{2 \mathrm{n}^{-}}(n=1,2,8)$ and arylene $\left(-\mathrm{p}-\mathrm{C}_{6} \mathrm{H}_{4}\right.$ - and $\left.-\mathrm{p}-\mathrm{C}_{6} \mathrm{H}_{4}-\mathrm{p}-\mathrm{C}_{6} \mathrm{H}_{4}-\right)$ bridges clearly demonstrated that the $n$-butanol flux goes up when the $\mathrm{CH}_{\mathrm{x}}: \mathrm{Si}$ ratio is increased from 1 to 6 or 12, while the water flux decreases (Castricum et al. 2011). The phenylene- and biphenylene-bridged systems led to lower increases of the $n$-butanol permeance than alkylene bridges with similarly high $\mathrm{CH}_{\mathrm{x}}: \mathrm{Si}$ ratios did. The effect of incorporated terminal alkyl groups $-\mathrm{C}_{\mathrm{n}} \mathrm{H}_{2 \mathrm{n}+1}$ with $n=1,2,3,6$, and 10 was demonstrated in a follow-up study (see Fig. 7). An increasing separation factor for $n$-butanol was seen when the chain length was increased, with a separation factor $\alpha_{\mathrm{BuOH} / \mathrm{H} 2 \mathrm{O}}=14$ for $\mathrm{CH}_{\mathrm{x}}: \mathrm{Si}=5$ (Paradis et al. 2013). 


\section{Gas Separation}

The obvious difference between gas and liquid separations is the much smaller concentrations in the feed stream in the case of gas separation (Kanezashi et al. 2009). The size differences between molecules in the gas phase are usually smaller than in the liquid phase, while polar (or even electrostatic) interactions between pore wall and gas molecule are absent in many cases. This is the reason that many gas separations work on the principle of molecular sieving by size selection, in particular for industrially relevant nonpolar gases like $\mathrm{H}_{2}, \mathrm{~N}_{2}, \mathrm{CH}_{4}$, and $\mathrm{CO}$ (Agirre et al. 2014). The kinetic diameters of small gases differ less than $0.1 \mathrm{~nm}$ from each other $\left(\mathrm{H}_{2} 0.29 \mathrm{~nm}, \mathrm{CO}_{2} 0.33, \mathrm{~N}_{2} 0.36, \mathrm{CO} 0.37, \mathrm{CH}_{4} 0.38 \mathrm{~nm}\right)$, so a very sharp pore size cutoff is required to obtain highly selective membranes. An exception is carbon dioxide, which behaves differently from the others. $\mathrm{CO}_{2}$ is thought to diffuse through the porous network via a surface diffusion mechanism that involves the adsorption of the $\mathrm{CO}_{2}$ molecule (Castricum et al. 2011).

Very high separation factors have been reported for amorphous microporous silica, even up to $\mathrm{H}_{2} / \mathrm{N}_{2}>4000$ (de Vos and Verweij 1998). MTES-derived methylated silica membranes show considerably lower permselectivities (de Vos et al. 1999). Permselectivities have also been quite moderate for gas separation by hybrid organosilica membranes (Kanezashi et al. 2009), and a considerable improvement is required to achieve comparable permselectivities as were already obtained with microporous silica (Kanezashi et al. 2009; Kreiter et al. 2011).

The low permselectivity is attributed to the relatively larger pore sizes of $-\mathrm{C}_{2} \mathrm{H}_{4}$ and $-\mathrm{C}_{2} \mathrm{H}_{2}$ - bridged silicas compared to microporous $\mathrm{SiO}_{2}$. As discussed above, a small but considerable fraction of pores with a pore diameter $>0.4 \mathrm{~nm}$ is present. Since most gases are $<0.4 \mathrm{~nm}$, the theoretically achievable permselectivity for small gases is limited. Even BTESM-derived membranes only have slightly higher selectivity than BTESE-derived membranes in $\mathrm{H}_{2}$ separation (see Fig. 5). Reported ideal permselectivities are 15-21 for $\mathrm{H}_{2} / \mathrm{N}_{2}$ and 7-9 for $\mathrm{H}_{2} / \mathrm{CH}_{4}$ (Kreiter et al. 2011). BTESM is selective in the separation of hydrocarbons with kinetic diameters $>0.4 \mathrm{~nm}$, e.g., $\mathrm{C}_{2} \mathrm{H}_{6}(0.42 \mathrm{~nm})$, i- $\mathrm{C}_{4} \mathrm{H}_{10}(0.54 \mathrm{~nm})$ (Kanezashi et al. 2013), and the separation of propene $(0.46 \mathrm{~nm})$ from propane $(0.50 \mathrm{~nm})$ (Kanezashi et al. 2012a, b). In agreement with expectation, longer and stiffer bridges lead to larger pores and therefore to lower permselectivities (Castricum et al. 2011; Xu et al. 2014).

It was shown recently that the gas selectivity of BTESE membranes can be improved considerably to a permselectivity $\mathrm{H}_{2} / \mathrm{N}_{2}>400$ by careful engineering of the pore structure during membrane fabrication (Castricum et al. 2015). By employing sols with a low acid ratio $\left(\left[\mathrm{H}^{+}\right] /[\mathrm{Si}]=0.01\right)$ and by coating them onto supports that had been pre-dried at low relative humidity $(\mathrm{RH}=0.5 \%)$, a hybrid membrane network was formed that contained a considerably lower fraction of pores $>0.35 \mathrm{~nm}$ than membranes obtained at higher acid ratios and/or higher humidity (see Fig. 8). The permeance of gases $<0.35 \mathrm{~nm}$ like $\mathrm{He}, \mathrm{H}_{2}$, and $\mathrm{CO}_{2}$ was not affected by changes in the membrane preparation process. It is hypothesized that both the absence of a high concentration of protons (Castricum et al. 2014) and the absence of water lead to more densified silica network in which larger pores are 


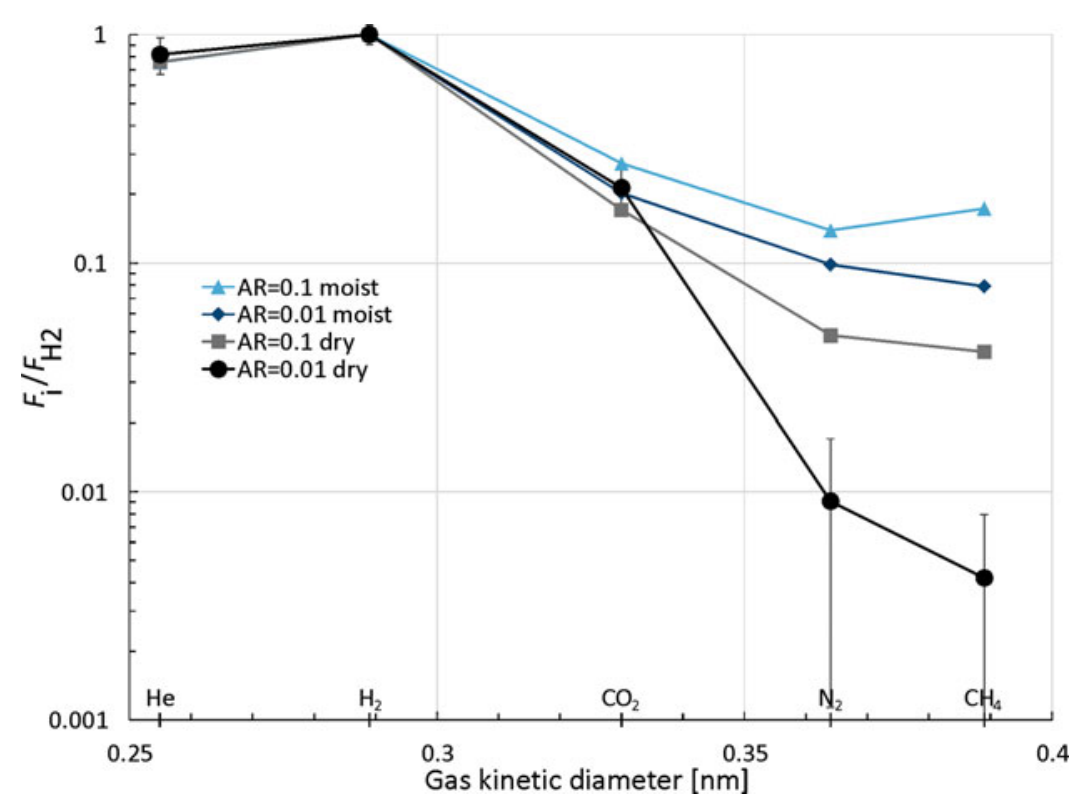

Fig. 8 Normalized single gas permeances of BTESE-based membranes prepared with acid ratio $\left[\mathrm{H}^{+}\right] /[\mathrm{Si}]=0.01$ or 0.1 , coated onto support systems pretreated at $\mathrm{RH}=0.5 \%$ ("dry") or $90 \%$ ("moist"). Reference permeance is hydrogen flux at $473 \mathrm{~K}, \Delta \mathrm{p}=2$ bar (Reprinted from Castricum et al. (2015) with permission from Elsevier)

virtually absent. Formation of larger pores can thus be understood as resulting somehow from a higher condensation rate and/or longer drying times when abundant water is present.

Next to hydrogen separation membranes, there is also a clear need for $\mathrm{CO}_{2}-$ selective membranes, as upcoming $\mathrm{CO}_{2}$ sequestration technologies require energyefficient separation of $\mathrm{CO}_{2}$ from (exhaust) gases. However, well-performing membranes are lacking. Unlike most nonpolar gases, the activation energy of $\mathrm{CO}_{2}$ permeance in silica and methylated silica membranes is typically below zero, and this is also the case in hybrid organosilica (Castricum et al. 2011). The activation energy of permeance is essentially the activation energy of diffusion minus the heat of sorption of the gas molecule on the pore wall (ten Elshof et al. 2003). For nonpolar gases, the temperature dependency of permeance is usually positive or slightly negative, i.e., values between -1 and $+2 \mathrm{~kJ} / \mathrm{mol}$ are normal. The more negative activation energy for $\mathrm{CO}_{2}$ suggests that its transport path is influenced by chemical interactions (exothermic adsorption) with the hybrid silica matrix. Since the activation energy of hydrogen permeance is positive, $\mathrm{a} \mathrm{CO}_{2}$ separation membrane operates ideally at an as low as possible operating temperature so that adsorption of $\mathrm{CO}_{2}$ is maximal, while $\mathrm{H}_{2}$ permeance is minimal. For most other separations, higher operating temperatures are usually desired because of higher fluxes and improved selectivities. The permeance of $\mathrm{CO}_{2}$ also decreases with increasing gas pressure, due 
to partial pore blocking resulting from pore filling with condensed $\mathrm{CO}_{2}$ (Castricum et al. 2011). The permeances of the other, inert gases are not influenced by pressure.

Dispersion of niobium $(\mathrm{Nb})$ into a microporous silica membrane $(\mathrm{Nb}: \mathrm{Si}=1: 3)$ has been shown to suppress the transport rate of $\mathrm{CO}_{2}$ (Boffa et al. 2008). This was explained by the formation of acidic $\mathrm{Nb}$ sites in the matrix structure leading to strong gas adsorption. The same approach was also pursued for BTESE-derived silica (Qi et al. 2010, 2012; Qureshi et al. 2015), but in these cases, the phenomenon was either observed or not, depending on the pretreatment of the BTESE membrane. Low $\mathrm{CO}_{2}$ permeances were observed when the system was annealed at high temperatures $\left(400-550{ }^{\circ} \mathrm{C}\right.$ in $\mathrm{N}_{2}$ ) (Qi et al. 2012) but not when lower annealing temperatures $\left(300^{\circ} \mathrm{C}\right.$ in $\mathrm{N}_{2}$ ) were employed (Qureshi et al. 2015). BTESE is known to be stable at $300{ }^{\circ} \mathrm{C}$, but (partial) thermal degradation of the organic bridges may occur above $400^{\circ} \mathrm{C}$ (Agirre et al. 2014; Qi et al. 2012), and this may have influenced the permselectivity of the membrane toward $\mathrm{CO}_{2}$ in those respective cases. Other dopants in BTESE and BTESM matrices that have been tested are Al (Kanezashi et al. 2013), B, and $\mathrm{Ta}$ (all $300{ }^{\circ} \mathrm{C}$ in $\mathrm{N}_{2}$ ) (Qureshi et al. 2015), but also in these cases, no specific influence on $\mathrm{CO}_{2}$ permeability was observed. However, both transition metal doping and the use of low dip sol concentrations during membrane fabrication contribute to the formation of more gas-permeable membranes in general (Qureshi et al. 2013, 2015).

In general, the same general trends in gas permeation behavior are observed in hybrid organosilicas with varying alkylene and phenylene bridges as in silica and methylated silica (MTES derived), irrespective of the type of gas and the type of bridging group. The only exception is the $-\mathrm{C}_{8} \mathrm{H}_{16}$ - bridged membrane, which shows relatively high activation energies of gas permeance $\left(+6 \mathrm{~kJ} / \mathrm{mol}\right.$ for $\mathrm{He}, \mathrm{H}_{2}, \mathrm{~N}_{2}$, and $\mathrm{CH}_{4}$ and $+2 \mathrm{~kJ} / \mathrm{mol}$ for $\mathrm{CO}_{2}$ ) (Castricum et al. 2011). Since the end-to-end lengths in a biphenylene-bridged precursor are similar to that of an octylene bridge, the difference is likely associated with the stiffness of the bridging group. The long and flexible $-\mathrm{C}_{8} \mathrm{H}_{16}$ - bridges seem to have a retarding effect on the transport rate of all gases, probably as a result of pore blocking. The effect increases with temperature, probably due to thermal vibrations and conformational changes of the octylene bridge that slow down gas transport further. Shorter and more rigid bridges are apparently beneficial for high transport rates.

Relatively high permselectivities were observed for $\mathrm{C}_{8} \mathrm{H}_{16-}$, phenylene-, and biphenylene-bridged membranes. The larger pore sizes seem to be beneficial for affinity-based selection at high temperature (Castricum et al. 2011). Hence, the permeability of gases depends on the size, stiffness, and nature of the organic bridging group, and in this way, the selectivity of hybrid silica membranes can be tailored toward certain targeted molecules.

Recently, more complex functional groups to tailor the transport properties of hybrid membranes have been reported. A malonamide-bridged hybrid membrane with an ability to disperse transition metal ions homogeneously throughout the matrix has been reported (Besselink et al. 2015). As examples both $\mathrm{Ce}^{4+}$ and $\mathrm{Ni}^{2+}$ were doped into a hybrid organosilica membrane. Also a triazine-functional hybrid silica membrane based on a novel solgel precursor with a high $\mathrm{H}_{2} / \mathrm{SF}_{6}$ selectivity and 
a high affinity for propene/propane separation has been reported (Ibrahim et al. 2014a, b). Functionalization of the hybrid matrix by co-condensation of BTESE with an amine-functional silane precursor has also been reported (Paradis et al. 2012).

\section{Conclusions}

Hybrid organosilica membranes based on solgel-processed-bridged silsesquioxane precursors are the first generation of oxide-based molecular separation membranes that show great promise for actual application in industrially relevant gas and liquid separation processes. Since the number of possible bridging groups is virtually infinite, many other functional groups may be covalently incorporated into the hybrid silica matrix, resulting in novel molecular sieving membranes with yet unexplored and possibly unprecedented performance in certain separations. We expect to see new types of membranes based on this principle in the forthcoming years.

\section{References}

Adewole JK, Ahmad AL, Ismail S, Leo CP. Current challenges in membrane separation of $\mathrm{CO}_{2}$ from natural gas: a review. Int J Greenhouse Gas Control. 2013;17:46-65.

Agirre I, Guemez MB, van Veen HM, Motelica A, Vente JF, Arias PL. Acetalization reaction of ethanol with butyraldehyde coupled with pervaporation. Semi-batch pervaporation studies and resistance of HybSi (R) membranes to catalyst impacts. J Membr Sci. 2011;371(1-2):179-88.

Agirre I, Arias PL, Castricum HL, Creatore M, ten Elshof JE, Paradis GG, et al. Hybrid organosilica membranes and processes: status and outlook. Sep Purif Technol. 2014;121:2-12.

Besselink R, Venkatachalam S, van Wullen L, ten Elshof J. Incorporation of niobium into bridged silsesquioxane based silica networks. J Sol-Gel Sci Technol. 2014;70(3):473-81.

Besselink R, Qureshi HF, Winnubst L, ten Elshof JE. A novel malonamide bridged silsesquioxane precursor for enhanced dispersion of transition metal ions in hybrid silica membranes. Microporous Mesoporous Mater. 2015;214:45-53.

Boffa V, ten Elshof JE, Petukhov AV, Blank DHA. Microporous niobia-silica membrane with very low $\mathrm{CO}_{2}$ permeability. ChemSusChem. 2008;1(5):437-43.

Boffa V, Castricum HL, Garcia R, Schmuhl R, Petukhov AV, Blank DHA, et al. Structure and growth of polymeric niobia-silica mixed-oxide sols for microporous molecular sieving membranes: a SAXS study. Chem Mater. 2009;21(9):1822-8.

Boffa V, Magnacca G, Jorgensen LB, Wehner A, Dornhofer A, Yue YZ. Toward the effective design of steam-stable silica-based membranes. Microporous Mesoporous Mater. 2013;179:242-9.

Brinker CJ, Scherer GW. Sol-gel science: the physics and chemistry of sol-gel processing. Boston: Academic; 1990.912 p.

Campaniello J, Engelen CWR, Haije WG, Pex P, Vente JF. Long-term pervaporation performance of microporous methylated silica membranes. Chem Commun. 2004;7:834-5.

Castricum HL, Kreiter R, van Veen HM, Blank DHA, Vente JF, ten Elshof JE. High-performance hybrid pervaporation membranes with superior hydrothermal and acid stability. J Membr Sci. 2008a;324(1-2):111-8. 
Castricum HL, Sah A, Geenevasen JAJ, Kreiter R, Blank DHA, Vente JF, et al. Structure of hybrid organic-inorganic sols for the preparation of hydrothermally stable membranes. J Sol-Gel Sci Technol. 2008b;48(1-2):11-7.

Castricum HL, Sah A, Kreiter R, Blank DHA, Vente JF, ten Elshof JE. Hybrid ceramic nanosieves: stabilizing nanopores with organic links. Chem Commun. 2008c;9:1103-5.

Castricum HL, Sah A, Kreiter R, Blank DHA, Vente JF, ten Elshof JE. Hydrothermally stable molecular separation membranes from organically linked silica. J Mater Chem. 2008d;18 (18):2150-8.

Castricum HL, Paradis GG, Mittelmeijer-Hazeleger MC, Kreiter R, Vente JF, ten Elshof JE. Tailoring the separation behavior of hybrid organosilica membranes by adjusting the structure of the organic bridging group. Adv Funct Mater. 2011;21(12):2319-29.

Castricum HL, Paradis GG, Mittelmeijer-Hazeleger MC, Bras W, Eeckhaut G, Vente JF, et al. Tuning the nanopore structure and separation behavior of hybrid organosilica membranes. Microporous Mesoporous Mater. 2014;185:224-34.

Castricum HL, Qureshi HF, Nijmeijer A, Winnubst L. Hybrid silica membranes with enhanced hydrogen and $\mathrm{CO}_{2}$ separation properties. J Membr Sci. 2015;488:121-8.

Chang KS, Yoshioka T, Kanezashi M, Tsuru T, Tung KL. A molecular dynamics simulation of a homogeneous organic-inorganic hybrid silica membrane. Chem Commun. 2010;46 (48):9140-2.

Chang KS, Yoshioka T, Kanezashi M, Tsuru T, Tung KL. Molecular simulation of micro-structures and gas diffusion behavior of organic-inorganic hybrid amorphous silica membranes. J Membr Sci. 2011;381(1-2):90-101.

Chapman PD, Oliveira T, Livingston AG, Li K. Membranes for the dehydration of solvents by pervaporation. J Membr Sci. 2008;318(1-2):5-37.

de Vos RM, Verweij H. High-selectivity, high-flux silica membranes for gas separation. Science. 1998;279(5357):1710-1.

de Vos RM, Maier WF, Verweij H. Hydrophobic silica membranes for gas separation. J Membr Sci. 1999;158(1-2):277-88.

Dubois G, Volksen W, Magbitang T, Miller RD, Gage DM, Dauskardt RH. Molecular network reinforcement of sol-gel glasses. Adv Mater. 2007;19(22):3989-94.

Elferink WJ, Nair BN, DeVos RM, Keizer K, Verweij H. Sol-gel synthesis and characterization of microporous silica membranes.2. Tailor-making porosity. J Colloid Interface Sci. 1996;180(1):127-34.

Fotou GP, Lin YS, Pratsinis SE. Hydrothermal stability of pure and modified microporous silica membranes. J Mater Sci. 1995;30(11):2803-8.

Gallego-Lizon T, Edwards E, Lobiundo G, dos Santos LF. Dehydration of water/t-butanol mixtures by pervaporation: comparative study of commercially available polymeric, microporous silica and zeolite membranes. J Membr Sci. 2002;197(1-2):309-19.

Glatter O, Kratky O. Small angle X-ray scattering. London: Academic Press. 1982: 525 p.

Ibrahim SM, Xu R, Nagasawa H, Naka A, Ohshita J, Yoshioka T, et al. A closer look at the development and performance of organic-inorganic membranes using 2,4,6-tris- 3 (triethoxysilyl)-1-propoxyl -1,3,5-triazine (TTESPT). RSC Adv. 2014a;4(24):12404-7.

Ibrahim SM, Xu R, Nagasawa H, Naka A, Ohshita J, Yoshioka T, et al. Insight into the pore tuning of triazine-based nitrogen-rich organoalkoxysilane membranes for use in water desalination. RSC Adv. 2014b;4(45):23759-69.

Kanezashi M, Yada K, Yoshioka T, Tsuru T. Design of silica networks for development of highly permeable hydrogen separation membranes with hydrothermal stability. J Am Chem Soc. 2009;131(2):414-5.

Kanezashi M, Yada K, Yoshioka T, Tsuru T. Organic-inorganic hybrid silica membranes with controlled silica network size: preparation and gas permeation characteristics. J Membr Sci. 2010;348(1-2):310-8.

Kanezashi M, Kawano M, Yoshioka T, Tsuru T. Organic-inorganic hybrid silica membranes with controlled silica network size for propylene/propane separation. Ind Eng Chem Res. 2012a;51 (2):944-53. 
Kanezashi M, Shazwani WN, Yoshioka T, Tsuru T. Separation of propylene/propane binary mixtures by bis(triethoxysilyl) methane (BTESM)-derived silica membranes fabricated at different calcination temperatures. J Membr Sci. 2012b;415:478-85.

Kanezashi M, Miyauchi S, Nagasawa H, Yoshioka T, Tsuru T. Pore size control of Al-doping into bis (triethoxysilyl) methane (BTESM)-derived membranes for improved gas permeation properties. RSC Adv. 2013;3(30):12080-3.

Kanezashi M, Miyauchi S, Nagasawa H, Yoshioka T, Tsuru T. Gas permeation properties through Al-doped organosilica membranes with controlled network size. J Membr Sci. 2014;466:246-52.

Keizer K, Uhlhorn RJR, Vanvuren RJ, Burggraaf AJ. Gas separation mechanisms in microporous modified gamma- $\mathrm{Al}_{2} \mathrm{O}_{3}$ membranes. J Membr Sci. 1988;39(3):285-300.

Kreiter R, Rietkerk MDA, Castricum HL, van Veen HM, ten Elshof JE, Vente JF. Stable hybrid silica nanosieve membranes for the dehydration of lower alcohols. ChemSusChem. 2009;2 (2):158-60.

Kreiter R, Rietkerk MDA, Castricum HL, van Veen HM, ten Elshof JE, Vente JF. Evaluation of hybrid silica sols for stable microporous membranes using high-throughput screening. J Sol-Gel Sci Technol. 2011;57(3):245-52.

Leenaars AFM, Keizer K, Burggraaf AJ. The preparation and characterization of alumina membranes with ultra-fine pores. J Mater Sci. 1984;19(4):1077-88.

Lin MY, Lindsay HM, Weitz DA, Ball RC, Klein R, Meakin P. Universality in colloid aggregation. Nature. 1989;339(6223):360-2.

Lin YS, Kumakiri I, Nair BN, Alsyouri H. Microporous inorganic membranes. Sep Purif Methods. 2002;31(2):229-379.

Loy DA, Carpenter JP, Myers SA, Assink RA, Small JH, Greaves J, et al. Intramolecular condensation reactions of alpha, omega-bis(triethoxysilyl)alkanes. Formation of cyclic disilsesquioxanes. J Am Chem Soc. 1996;118(35):8501-2.

Lu GQ, da Costa JCD, Duke M, Giessler S, Socolow R, Williams RH, et al. Inorganic membranes for hydrogen production and purification: a critical review and perspective. J Colloid Interface Sci. 2007;314(2):589-603.

Maene N, Nair BN, D'Hooghe P, Nakao SI, Keizer K. Silica-polymers for processing gas separation membranes: high temperature growth of fractal structure. J Sol-Gel Sci Technol. 1998;12(2):117-34.

Nair BN, Keizer K, Suematsu H, Suma Y, Kaneko N, Ono S, et al. Synthesis of gas and vapor molecular sieving silica membranes and analysis of pore size and connectivity. Langmuir. 2000;16(10):4558-62.

Ockwig NW, Nenoff TM. Membranes for hydrogen separation. Chem Rev. 2007;107 (10):4078-110.

Paradis GG, Kreiter R, van Tuel MMA, Nijmeijer A, Vente JF. Amino-functionalized microporous hybrid silica membranes. J Mater Chem. 2012;22(15):7258-64.

Paradis GG, Shanahan DP, Kreiter R, van Veen HM, Castricum HL, Nijmeijer A, et al. From hydrophilic to hydrophobic HybSi (R) membranes: a change of affinity and applicability. J Membr Sci. 2013;428:157-62.

Prabhu AK, Oyama ST. Highly hydrogen selective ceramic membranes: application to the transformation of greenhouse gases. J Membr Sci. 2000;176(2):233-48.

Qi H, Han J, Xu NP, Bouwmeester HJM. Hybrid organic-inorganic microporous membranes with high hydrothermal stability for the separation of carbon dioxide. ChemSusChem. 2010;3 (12):1375-8.

Qi H, Chen HR, Li L, Zhu GZ, Xu NP. Effect of Nb content on hydrothermal stability of a novel ethylene-bridged silsesquioxane molecular sieving membrane for $\mathrm{H}_{2} / \mathrm{CO}_{2}$ separation. J Membr Sci. 2012;421:190-200.

Qureshi HF, Nijmeijer A, Winnubst L. Influence of sol-gel process parameters on the microstructure and performance of hybrid silica membranes. J Membr Sci. 2013;446:19-25.

Qureshi HF, Besselink R, ten Elshof JE, Nijmeijer A, Winnubst L. Doped microporous hybrid silica membranes for gas separation. J Sol-Gel Sci Technol. 2015;75(1):180-8. 
Sekulic J, Luiten MWJ, ten Elshof JE, Benes NE, Keizer K. Microporous silica and doped silica membrane for alcohol dehydration by pervaporation. Desalination. 2002;148(1-3):19-23.

Sekulic J, ten Elshof JE, Blank DHA. A microporous titania membrane for nanofiltration and pervaporation. Adv Mater. 2004;16(17):1546-50.

Shea KJ, Loy DA. A mechanistic investigation of gelation. The sol-gel polymerization of precursors to bridged polysilsesquioxanes. Acc Chem Res 2001;34(9):707-16.

Shimoyama T, Yoshioka T, Nagasawa H, Kanezashi M, Tsuru T. Molecular dynamics simulation study on characterization of bis(triethoxysilyl)-ethane and bis(triethoxysilyl)ethylene derived silica-based membranes. Desalin Water Treat. 2013;51(25-27):5248-53.

Spijksma GI, Huiskes C, Benes NE, Kruidhof H, Blank DHA, Kessler VG, et al. Microporous zirconia-titania composite membranes derived from diethanolamine-modified precursors. Adv Mater. 2006;18(16):2165-8.

ten Elshof JE, Abadal CR, Sekulic J, Chowdhury SR, Blank DHA. Transport mechanisms of water and organic solvents through microporous silica in the pervaporation of binary liquids. Microporous Mesoporous Mater. 2003;65(2-3):197-208.

Tsuru T, Takata Y, Kondo H, Hirano F, Yoshioka T, Asaeda M. Characterization of sol-gel derived membranes and zeolite membranes by nanopermporometry. Sep Purif Technol. 2003;32 (1-3):23-7.

Tsuru T, Shintani H, Yoshioka T, Asaeda M. A bimodal catalytic membrane having a hydrogenpermselective silica layer on a bimodal catalytic support: preparation and application to the steam reforming of methane. Appl Catal A Gen. 2006;302(1):78-85.

Tsuru T, Shibata T, Wang JH, Lee HR, Kanezashi M, Yoshioka T. Pervaporation of acetic acid aqueous solutions by organosilica membranes. J Membr Sci. 2012;421:25-31.

Uhlhorn RJR, Keizer K, Burggraaf AJ. Gas and surface diffusion in modified gamma-alumina systems. J Membr Sci. 1989;46(2-3):225-41.

Uhlhorn RJR, Keizer K, Burggraaf AJ. Gas-transport and separation with ceramic membranes. 2. Synthesis and separation properties of microporous membranes. J Membr Sci. 1992;66 (2-3):271-87.

van Veen HM, Rietkerk MDA, Shanahan DP, van Tuel MMA, Kreiter R, Castricum HL, et al. Pushing membrane stability boundaries with $\mathrm{HybSi}(\mathrm{R})$ pervaporation membranes. J Membr Sci. 2011;380(1-2):124-31.

Wei Q, Wang F, Nie ZR, Song CL, Wang YL, Li QY. Highly hydrothermally stable microporous silica membranes for hydrogen separation. J Phys Chem B. 2008;112(31):9354-9.

$\mathrm{Xu}$ R, Ibrahim SM, Kanezashi M, Yoshioka T, Ito K, Ohshita J, et al. New insights into the microstructure-separation properties of organosilica membranes with ethane, ethylene, and acetylene bridges. ACS Appl Mater Interfaces. 2014;6(12):9357-64.

Zhang Y, Sunarso J, Liu SM, Wang R. Current status and development of membranes for $\mathrm{CO}_{2} / \mathrm{CH}_{4}$ separation: a review. Int J Greenhouse Gas Control. 2013;12:84-107. 